\title{
Combining Expressive Writing with an Affect- and Attachment-Focused Psychotherapeutic Approach in the Treatment of a Single-Incident Trauma Survivor: The Case of "Grace"
}

\author{
ERICA R. PASS ${ }^{a, b, c}$
}

\author{
${ }^{\text {a }}$ Graduate School of Applied and Professional Psychology, Rutgers University \\ ${ }^{\mathrm{b}}$ Correspondence concerning this article should be addressed to Erica R. Pass, Graduate School of Applied and \\ Professional Psychology, Rutgers University, 152 Frelinghuysen Road, Piscataway, NJ 08854 \\ Email: erica.pass@rutgers.edu \\ C Note: This article is a reformatted version of my dissertation (Pass, 2010).
}

\begin{abstract}
The idea of using a phase-oriented model in the treatment of trauma is an established one. The first phase aims to establish safety, stabilization, and trust before moving onto the second phase, which involves more direct and intensive processing of trauma. The third phase serves to consolidate and integrate the gains made in treatment. The purpose of this study is to determine whether utilizing a phase-oriented model that combines Accelerated Experiential Dynamic Psychotherapy (AEDP), an affect and attachment-focused experiential treatment, with expressive writing enhanced the treatment of "Grace," a single-incident trauma survivor. While both AEDP and expressive writing are well developed methods, their combination has not been tried before. Focusing on a survivor of a single-incident trauma was chosen to best implement the goal of writing about a concrete traumatic event. In line with the three-phase approach, the "AEDPWriting" model first utilizes AEDP to build a secure attachment as well as affect tolerance, setting the stage for deeper exploration of a patient's traumatic history. Second, the expressive writing component then builds on this base by directly addressing the traumatic incident and processing it in a deeper and more comprehensive manner. Finally, utilizing both the AEDP and expressive writing approaches, the third phase involves reflection on the work done, consolidation, and celebration of the patient's true self state of being.
\end{abstract}

Key words: Accelerated Experiential Dynamic Psychotherapy (AEDP); Expressive Writing; psychotherapy integration; trauma case study; post-traumatic stress disorder (PTSD); case study; clinical case study

\section{CASE CONTEXT AND METHOD}

\section{The Rationale for Selecting This Particular Client for Study}

The present study utilizes a combination of an attachment- and affect-focused experiential therapeutic approach (Accelerated Experiential Dynamic Psychotherapy, or AEDP) with expressive writing. This treatment was designed and intended for use with a survivor of an 
isolated traumatic event, i.e., the index trauma. While formulating this combined treatment approach, I was ideally looking to work with clients who presented with ongoing posttraumatic symptoms (although not necessarily meeting all DSM-IV criteria for Posttraumatic Stress Disorder) resulting from an index trauma. I believed identifying an isolated incident would provide a concrete goal for the writing portion of the treatment; a clear event on which to focus. Based on past research with short-term dynamic therapies like AEDP, to enhance the matching of the client to the approach I was using, I employed inclusion and exclusion criteria that had been developed in this field, primarily from the work of Hanna Levenson with her time-limited dynamic psychotherapy model (1995). (For the criteria I employed, see Table 1 at the end of this document).

The focal case of this study, hereafter referred to by the pseudonym "Grace," fit the above description. A 24-year-old woman, she presented with several posttraumatic symptoms resulting from an incident that had occurred four years prior, and she met the inclusion/exclusion criteria in Table 1. Her history of an isolated index trauma, which continued to cause severe distress, along with Grace's apparent capacity to trust and build rapport with me and engage in what was expected to be at times intensive psychotherapy were predicted to be the most important determinants of a successful treatment.

\section{The Clinical Setting in Which the Case Took Place}

The setting was a clinic within the community. The fee was reasonable and set according to the client's financial ability to pay. At the time of the therapy, I was an advanced doctoral clinical psychology student, was taking a course in short-term dynamic therapy, and was supervised after each therapy session by a senior clinical psychologist with in-depth theoretical and clinical background in the treatment of trauma as well as knowledge of the AEDP model. This case study constituted my doctoral dissertation, and the research design-including both oral and written permission by the client agreeing to participate in the case study—was thus approved by the Institutional Review Committee of my university. The treatment lasted 40 weekly sessions.

I was assigned Grace's case as the applied portion of a course in short-term dynamic psychotherapy. Due to the nature of Grace's trauma, I opted not to use a more traditional shortterm treatment of 12 sessions or so, and chose instead to pursue a model inspired by the experiential short-term dynamic philosophies but with a heavier focus on attachment and affect tolerance.

\section{The Methodological Strategies Employed for Enhancing the Rigor of the Study}

All sessions were recorded on DVD and subsequently reviewed by the therapist. As mentioned above, each DVD was additionally viewed by a supervisor (a clinical psychologist), who was then able to provide additional insight and guidance. I met weekly with my supervisor for the purposes of reviewing progress made and assessing the emotional state of the client from 
week to week. This was invaluable to both the treatment and to my growth and development as a clinical psychologist in training.

In addition, two quantitative measures were used. These measures and the results in using them are discussed below in the fourth section on assessment and the eighth section on outcome.

\section{Sources of Data Available Concerning the Client}

Before the therapy began, no information was available to me as the therapist beyond the results of an initial phone intake done with the client by the clinic staff.

\section{Confidentiality}

Confidentiality is maintained by including no information in this case study by which the client can be recognized; in other words, all information has been de-identified and in some cases further disguised in order to avoid identification. That said, I have strived to maintain as much clinical authenticity and accuracy as possible in the case study.

\section{THE CLIENT}

"Grace" came to treatment seeking relief from a single-incident trauma that had occurred four years prior: she was the first to find her brother's body after he had hung himself in her bedroom. A 24-year-old, married, Caucasian female, she presented with several symptoms that fit the main symptom categories of Posttraumatic Stress Disorder as defined by the American Psychiatric Association's (2000) Diagnostic Statistical Manual-IV-TR. Specifically, these symptoms included intrusive thoughts, flashbacks, being easily triggered, irritability, outbursts of anger, and avoidance of stimuli associated with the trauma. A personable young woman, Grace's anxiety early in the treatment was apparent in her pressured and at times circumstantial speech. Grace, who worked as a paralegal, lived with her husband. He was a source of considerable support, although Grace was afraid that her irritability and mood lability were endangering their relationship. Prior to our work together, Grace had attended one session of an outpatient group aimed at survivors of suicide but did not return because she found the stories of the numerous other members to be overwhelming. She had not been in individual treatment before. Our treatment would ultimately last 40 sessions.

\section{GUIDING CONCEPTION, WITH RESEARCH AND CLINICAL EXPERIENCE SUPPORT}

\section{Three Phases}

The therapeutic model utilized in Grace's case consisted of two major components: (a) Fosha's (2000) affect- and attachment-focused Accelerated Experiential Dynamic Psychotherapy 
(AEDP); and (b) expressive writing (Calhoun \& Resick, 1993). Both have been developed and utilized with survivors of trauma, although not in combination. (I will hereafter refer to the combination as the "AEDP-Writing" model.) As explained below, the AEDP-Writing model follows a tradition in trauma therapy of organizing the therapy into three phases, using AEDP to lay the groundwork for an effective, secure working alliance with rapport and a sense of safety; familiarizing the patient with exploration of a range of affects; and setting the stage for deeper exploration of his or her trauma history. (Note that while AEDP is the featured model utilized in phase one, it continues to influence the treatment and therapist's actions throughout the treatment.)

Once these first-phase goals have been basically achieved, the second phase - the expressive writing component-begins with the goal of directly exposing the client to the target traumatic event and helping the client to process the event in a deeper and more comprehensive manner.

The third and final stage then involves: (a) reflection on the work done in the first two phases; (b) consolidation and continued integration of the changes made; and (c) celebration of the patient's true self state.

The idea of working in phases with trauma patients is not a new one. From writings about Pierre Janet's work in the $19^{\text {th }}$ century (van der Hart, Brown \& van der Kolk, 1989) to Judith Herman's (1992) discussion of traumatic disorders, phase-oriented treatment has been indicated for the treatment of trauma, with safety or stabilization the goal of the first phase; exploration of traumatic memories, remembrance, and mourning the goal of the second; and integration and reconnection the goal in the third. It should be noted that while these phases are generally sequential, there are times when they are not distinctly linear but instead overlap, with the therapist needing to be attuned to where the client is at any given time (Courtois, 1999).

\section{Accelerated Experiential Dynamic Psychotherapy (AEDP)}

Diana Fosha’s (2000) Accelerated Experiential Dynamic Psychotherapy (AEDP) model has its roots in Davanloo's (1980) Intensive Short-Term Dynamic Psychotherapy, and indeed, Fosha trained under Davanloo. However, AEDP does not take as aggressive a stance when working with a patient's defenses. Instead, Fosha chose to break from Davanloo's more confrontational style and focus more on the "melting" of defenses, via being present with the patient until intolerable affect becomes less so (Fosha, 2000). I chose Fosha's focus on attachment not only because it felt like a good fit for Grace, whose intimate attachments and relationships had been shaken by the nature of her trauma, but also because its "softer" and "gentler" approach suited my personality and preferred therapeutic style more than the aggressive style of Davanloo. (And in fact Grace proved capable of having her defenses challenged in the gentler style of AEDP. For more on the therapist's role in AEDP, see the section on this topic below.) 
Many short-term dynamic models utilize the "triangle of conflict" (Malan, 1976) in formulation. An inverted triangle, the lower point symbolizes the patient's genuine impulses or feelings, while one upper point signifies the patient's defenses against these feelings and the other upper point is the resultant anxiety when defenses don't work (Messer \& Warren, 1995). Fosha utilizes the triangle (sometimes called the "triangle of experience" [2007]) when conceptualizing as well: (a) the bottom is core-or authentic_-affect, which is often blocked, while the top corners are (b) defenses (either working to block genuine affective experience, or in some cases, authentic relational experience), and (c) what Fosha calls "red-signal affects," like anxiety and shame. A patient will often bounce back and forth between the top two corners in an effort to bypass dipping into core affect (Fosha, 2000).

As reflected in AEDP's name, "Accelerated Experiential Dynamic Psychotherapy," the AEDP model is influenced by several theories, including those experiential and psychodynamic in nature. For example, the "Experiential" part refers in part to therapies derived from Carl Rogers' (1964) "Client-Centered Therapy," particularly Greenberg's "Emotion-Focused Therapy" (e.g., Greenberg \& Safran, 1989; Greenberg \& Paivio, 1997; Greenberg \& Watson, 2005). The "Dynamic" part refers to psychodynamic object relations and attachment theory, rooted in the work of Winnicott (1965), Bowlby (1973, 1980, 1982), and Ainsworth et al (1978). In addition, AEDP finds influence in several other areas, including the emotion theory and affective neuroscience work of Damasio (1999), Panksepp (1998), and Schore (1994, 2001, 2003), among others.

Although not dismissing the achievement of insight, like Emotion-Focused Therapy, AEDP values the experience of genuine affect over the achievement of insight per se, particularly affect as experienced through the lens of a securely attached relationship (Fosha \& Slowiaczek, 1997). Indeed, in line with its attachment theory origins, the AEDP model aims for access to genuine affect while securely attached to an empathic and emotionally available other in the person of the therapist (Fosha, 2000). It looks for resilience and agency in its patients, as well as the activation of one's true self, similar to Winnicott's (1960/1965) concept of true and false selves, and the subsequent relishing of that self.

Fosha encourages the therapist to remain connected to the patient while core affect is being experienced: “AEDP seeks to effect its healing by facilitating the individual's visceral experience of core affective phenomena within an emotionally engaged patient-therapist dyad: the provision and fostering of new emotional experiences is both AEDP's method and its aim" (Fosha, 2003, p.224, italics hers). Indeed, Fosha writes that "AEDP has a two-factor theory of therapeutic change: It involves affect and relatedness.” (Fosha, 2003, p.231). Furthermore, it is the establishment of trust and a secure attachment between patient and therapist that enables deeper affective processing, including the processing of traumatic material, in treatment (Fosha, 2003). AEDP posits that access to genuine affect while securely attached to an empathic and emotionally available other can remedy a feeling of unbearable or "pathogenic aloneness" (Fosha, 2000). 
Ideally, AEDP treatment involves three states and two state transformations (Fosha, 2000, 2007). State 1 is defense, in which the patient is guarded against experiencing affect and/or relating to another. There is then a transformation seen, in which the patient transitions to State 2, which is core affect, in which the patient feels his or her emotion more authentically. Ideally, there is then another state transformation, in which the patient, via guided metatherapeutic processes by the therapist, experiences deeper affect as he or she reflects on the transformation that is occurring. The goal is to then reach State 3, or core state, in which the patient experiences a "truth sense" and feels calm, open, self-empathic, and natural.

As mentioned above, AEDP focuses on the concepts of "true self" and "self-at best" (Fosha 2000, 2002b). Fosha posits that one's "self-at-best" can be activated in moments of genuine connection when one is feeling undefended, authentic, and open to his or her core affect. Again, this is referred to as "core state," during which the patient experiences an increased sense of calm, clarity, and openness, as well as decreased anxiety and defensiveness (Fosha, 2007). Fosha notes that another core state experience is "the capacity to construct a coherent and cohesive autobiographical narrative” (2007, p.8). This idea ties in well to the expressive writing component of the AEDP-Writing model of therapy.

\section{The Role of the Patient in AEDP}

It is a goal of the AEDP therapist to aid the patient in achieving core state and then naming it when it comes to light. Similar to Emotion-Focused Therapy, this meta-therapeutic processing is another hallmark of AEDP (Fosha, 2000): by pausing the patient in session and calling attention to how he or she is experiencing the moment, the therapist encourages the patient to become increasingly aware of him or herself: relationally, affectively, somatically, and cognitively. Once this begins to happen consistently, it is additionally important to identify relationships and experiences outside of therapy that can also enable the patient to achieve this true self.

\section{The Role of the Therapist in AEDP}

Following its attachment theory roots, in AEDP the therapist aims to be a "true other" (Fosha, 2002b), attuned so that the patient's true self can then be actualized. The AEDP therapist brings his or her own affective honesty and bravery to the treatment. In addition, the therapist brings a willingness to engage in his or her own emotional processing and not shy away from challenging material and the full continuum of feeling, including not only emotions more "typically" seen in therapeutic treatments like grief, despair, and anger, but also a range of mastery and healing affects (Russell \& Fosha, 2008).

The AEDP therapist also aims to track the patient from moment to moment, striving to maintain attunement to shifts, however subtle, in the patient's presentation, whether they are paraverbal, nonverbal, or verbal. This is to allow the patient's true self to emerge via reflection and validation on the part of the therapist. According to Fosha, secure attachment is denoted by the ability, while related to an attachment object, to both feel-and-deal-in other words, to both 
experience and cope with affect. However, what often happens is that a person either feels without dealing (as in an insecurely-attached, resistant child who is overwhelmed by emotions); deals without feeling (as in an insecurely-attached, avoidant child who copes by going on autopilot without engaging emotions); or neither (as in a child with a disorganized attachment style). The ultimate goal is to feel and deal while relating to a safe other; this is referred to as affective competence (Fosha, 2000).

As an example of the feel-and-deal concept, when Grace presented for therapy, she had been fluctuating between dealing without feeling (keeping herself constantly busy, utilizing avoidance and manic defenses) until the feeling would build up and overwhelm her, resulting in feeling without dealing (in which she was flooded by affect and upsetting imagery). She described this latter state as wanting to "jump out of my skin...this thing comes over me, I get overwhelmed with emotion.” My goal for treatment was to help her reach a state of affective competence, in which she was simultaneously feeling and dealing while remaining connected to me.

\section{Empirical Support for AEDP}

While AEDP as a whole has not yet been empirically tested, it has been reviewed extensively via writings in scholarly journals and presented widely at conferences and workshops. In addition, Fosha, as well as other senior members of the AEDP Institute, have made available many illustrative therapy session transcripts to illustrate the model. In addition, the American Psychological Association offers an instructional video in which Fosha demonstrates the model (American Psychological Association, 2006; Fosha, 2006b).

Moreover, two of the main underlying components of AEDP-experiential therapy and psychodynamic therapy-have accrued empirical support. Specifically, in terms of experiential therapy, Elliott (2001) has summarized the positive-outcome results of 86 controlled and uncontrolled outcome studies. For example, one meta-analysis of a subset of 28 of these studies yielded an average pre- to post-therapy effect size of 1.1, which rose to a 1.2 overall effect size including follow-up data (Elliott, 2001). In addition, one version of experiential therapy, Greenberg et al.'s Emotion-Focused Therapy (1989, 1997, 2005), is listed as empirically supported on the Website of Research-Supported Psychological Treatments of the Society of Clinical Psychology (2010; also known as "Division 12 of the American Psychological Association").

Regarding psychodynamic therapy, a recent article by Shedler (2010) presented a metaanalytic study of 74 individual therapy outcome studies and concluded that

Empirical evidence supports the efficacy of psychodynamic therapy. Effect sizes for psychodynamic therapy are as large as those reported for other therapies that have been actively promoted as “empirically supported” and "evidence based.” In addition, patients who receive psychodynamic therapy maintain therapeutic gains and appear to continue to improve after treatment ends (p. 98). 
Shedler's analysis included a summary of a recent Cochrane Library study, known for its high level of rigor, by Abbass, Hancock, Henderson, and Kisely (2006). This study analyzed 23 randomized controlled trials of 1,431 patients in short-term psychodynamic (less than 40 sessions). The studies included patients with a range of common mental and emotional difficulties, including, depressive, anxiety, and somatoform disorders, frequently combined with interpersonal or personality disorders. Patients in psychodynamic therapy were compared with wait list, minimal treatment, or "treatment as usual" controls. The results yielded an overall effect size of 0.97 for general symptom improvement. The effect size increased to 1.51 when the patients were assessed at long-term follow-up (greater than nine months post-treatment).

In addition, on the above-mentioned Website of Research-Supported Psychological Treatments (Society of Clinical Psychology, 2010), three different psychodynamic treatments are listed as empirically supported (the first two short-term, and the third, long-term): Psychoanalytic Therapy for Panic Disorder, Short-Term Psychodynamic Therapy for Depression, and Transference-Focused Therapy for Borderline Personality Disorder.

\section{AEDP and Trauma}

Much like the concept in trauma theory that trauma survivors ideally learn to integrate their cognitions of a traumatic event with their resultant emotions, AEDP also aims to integrate the patient's affective, somatic, and cognitive experiences that are associated with the trauma.

One of AEDP's guiding therapeutic goals is to foster a deep interpersonal connection within the therapy, one which facilitates the exploration of memories that may have been locked away and frozen in time, as traumatic memories often are. Indeed, Fosha believes that a "safe and affect-friendly environment" should be a goal from the first session, as well as activating "a patient-therapist relationship in which it is clear that the patient is deeply valued and will not be alone with emotional experiences" (Fosha, 2003, p.245). Fosha believes that the treatment of trauma relies upon this rapport to help "undo" the client's feeling alone with his or her traumatic history, and to help the client begin to feel confident in tackling what can feel like overwhelming affect and disjointed memories (Fosha, 2003).

Fosha speaks of trauma as a "transformational opportunity," (2002a), and how both trauma and therapy often involve "quantum transformation" (2006a). As in AEDP generally, a main goal of AEDP treatment with trauma is to utilize the relationship between patient and therapist to provide enough safety and relational authenticity so that the patient is enabled to overcome blockages of active processing of the traumatic experience in order to reach a more content, genuine, and integrated state of being. Furthermore, Fosha believes that for healing to happen, the trauma must be addressed while in the presence of a caring and empathic other. It must not be "forgotten," as healing does not happen via numbing, detaching, or dissociating (Fosha, 2002a). As Fosha (2006a) writes, “There is a world of difference between being alone with overwhelming emotions and being with a trusted other in the affect storm" (p. 570). A related idea is expressed in the words of Gleiser, Ford, and Fosha (2008). They write that AEDP aims to help PTSD patients find relief via 
transforming diffuse distress, fear, and anxiety into more fully articulated and better regulated emotions, memories, and adaptive action on behalf of the self. Fundamental to AEDP is that its emotion-focused interventions are grounded in an experientially-explored, attachment-based therapeutic relationship (p. 345).

\section{Linking AEDP to Expressive Writing}

Drawing on the principles and strategies of AEDP outlined above, the general treatment plan of the AEDP-Writing model is to not only allow patients to connect with their traumatic memories while in the presence of a supportive other so that feelings can be more completely processed, but to also draw attention to positive emotions and healing experiences and encourage them to absorb these as well (Russell \& Fosha, 2008). Writes Fosha, "We do not want to only focus on the experience that must be undone and transcended, that is, the trauma. We must also focus, with equal devotion and discipline, on the experience of feeling relief and being helped" (2002a, p.15).

In this vein, the assigned writing activities focused both on traumatic memories as well as comforting and empowering ones, with the goal of integrating them into a more complete, holistic life story. The ultimate goal of both components of treatment-AEDP and expressive writing-was to facilitate the patient's accessing of his or her "true self” and true voice.

\section{Expressive Writing and Trauma}

The second component of the AEDP-Writing model involves a series of writing activities with the goal of progressing to exposing the client to his or her index trauma. Research has examined writing as a therapeutic approach, including with a trauma population (see review of research by Esterling et al., 1999).

James Pennebaker is the researcher most often linked with the healing benefits of writing. He has conducted several studies over the past three decades, empirically finding that there are both psychological and physiological benefits to writing (Pennebaker \& Beall, 1986; Pennebaker, Kiecolt-Glaser, \& Glaser, 1988; Pennebaker, 1997; Pennebaker \& Seagal, 1999). In 1988, Pennebaker, Kiecolt-Glaser, and Glaser conducted a randomized clinical trial with 50 undergraduate college students in which subjects were instructed to write about either personally troubling events or superficial topics for twenty minutes at a time for four consecutive days. The authors found that students who actively confronted traumatic memories via expressive writing showed improved immunity at a point six weeks post-experiment via measures of cellular immune-system functioning, decreased visits to the student health center, and self-report. At a three month follow-up, those in the disclosure group reported happier moods. In addition, in 1998, Smyth published a synthesis of the research on expressive writing done to date and concluded that throughout these studies, there were enhancements in four outcomes: reported physical health, psychological well-being, physiological functioning, and general functioning. 
Pennebaker claims that it is not just catharsis that helps a person heal from a traumatic experience, but also a deeper comprehension of the experience itself as well as increased selfunderstanding. With expressive writing, the intended aim is to increase the integration of cognition and affect, including specifically those cognitions and affects associated with a traumatic experience. Pennebaker (1997) speaks of the importance of confronting a traumatic memory as opposed to inhibiting it:

Confronting a trauma helps people understand and ultimately assimilate the event, ... [while inhibition] gradually undermines the body's defenses. ... [It is a] cumulative stressor on the body, increasing the probability of illness and other stress-related physical and psychological problems (pp. 2, 9, 10).

Pennebaker's repeated findings state that the forming of a narrative is essential when dealing with an overwhelming traumatic memory and that writing can serve to help a person organize complex emotional experiences (see review in Pennebaker \& Seagal, 1999). Importantly, this article also mentions a study done in Israel with 14 PTSD patients which suggested that expressive writing done without psychotherapeutic support in the form of cognitive and/or coping skills training may not be beneficial for this population (Gidron, Peri, Connolly, \& Shalev, 1996). Thus, in the AEDP-Writing approach, I planned on incorporating the expressive writing exercises into an established psychotherapeutic treatment. In addition, in their review of research done on the impact of expressive writing about past trauma from a mental and physical health perspective, Esterling, L'Abate, Murray and Pennebaker (1999) found that

Movement toward development of a narrative is far more predictive of health than having a coherent story per se. The construction of a story rather than having a constructed story, therefore, may be the desired end point of writing, and, by extension, psychotherapy” (1999, pp. 92-4, italics added).

Indeed, writing can aid in the transformation of the chaotic flashes of memory often seen in survivors of trauma into a more "organized mental framework” (Jacobs, 2004, p.15). In addition to aiding in the organization of chaotic memories, writing can act as a means of selfsoothing and relief (Jacobs, 2004). In her practice, in which she regularly uses journal therapy, Jacobs has found that writing can "help people either to elaborate or to consolidate improvement they make in therapy" (Jacobs, 2004, p.15), supporting the idea that writing can facilitate and deepen the processing that occurs in psychotherapy. Jacobs has published a book called "Writing for Emotional Balance" in which she details how journaling can serve to manage overwhelming affect.

Another researcher who has documented the value of writing within a psychotherapeutic frame is Patricia Resick (1993, 2008). Writing is a key component of Resick's Cognitive Processing Therapy (CPT) manualized protocol, a treatment that was initially found to be empirically supported in helping survivors of rape (Calhoun \& Resick, 1993), and later found to be empirically supported with helping veterans with combat-related trauma (Resick, Monson, \& Rizvi, 2008). One of the notable aspects of CPT is the use of writing on the part of the patient to 
confront traumatic memories. In addition, the patient is asked not just to recount his or her trauma but to also include sensory and affective details, i.e. how he or she felt, what he or she remembers seeing, hearing, feeling, etc. during the traumatic experience. Further, these assignments are read aloud in session to the therapist. Thus, there are two levels of processing happening, one via the writing exposure and one via the reading and sharing of the memory with the therapist. The patient is provided the opportunity to express his or her experience while in the presence of a safe other, reducing the feelings of shame and isolation that often plague trauma survivors: "telling one's story promotes a sense of knowing and being known" (McLeod, 2004). It should be noted that while both CPT and the AEDP-Writing model focus on both cognitive and affective processing, the CPT model places greater emphasis on cognition, and the AEDP-Writing model on affect, because of the focus in AEDP on affect (Gleiser, Ford \& Fosha, 2008).

Finally, Judith Herman, author of the seminal book Trauma and Recovery (1992), speaks of the importance for trauma patients to create a "trauma narrative" as an integral part of their therapy and healing (see also Lindner, 2004). Importantly, Herman also discusses the value of adding this aspect into the therapy once there is a lessening of the reported posttraumatic symptoms, as well as an established sense of safety for the patient. Following this logic, in the AEDP-Writing model, the strategy is only to add writing into the treatment when the patient appears ready, including the therapist's judgment that a sufficient trust and emotional bond with the patient has been established.

\section{Rationale for Combining AEDP and Expressive Writing}

As described above, the first phase in working with trauma survivors involves establishing rapport, trust, openness, a sense of safety, and familiarization with and tolerance of affect. In the AEDP-Writing model, this first phase begins with AEDP, since AEDP is explicitly embedded in attachment and relational theories (Fosha, 2002a, 2006; Gleiser, Ford \& Fosha, 2008). Once the first phase is completed, expressive writing activities are introduced in the second phase. These activities, which are more directive in nature, can still encourage and be a springboard for further exploration.

In addition, both AEDP and expressive writing proponents discuss the importance of both formation of a narrative as well as attention to a wide range of affective experience. AEDP greatly values "mastery affects," like joy and pride, and "healing affects," such as gratitude, and paying careful attention to be mindful of these experiences both within and outside of the therapy relationship (Russell \& Fosha, 2008). Similarly, in the expressive writing literature, Pennebaker (1997) talks about how positive events should also be given attention, as opposed to solely writing about stressful experiences; and Jacobs (2004) writes that giving attention to positive experiences challenges the idea that it's more important to pay attention to the "negative" ones. Above all, what researchers emphasize is the importance of reinforcing and validating experiences that bring about joy and gratitude, as opposed to neglecting them in favor of a sole focus on suffering and so-called negative emotions (which may-to some trauma victims-feel more therapeutically salient). 


\section{ASSESSMENT OF THE CLIENT'S PRESENTING PROBLEMS, GOALS, STRENGTHS, AND HISTORY}

\section{Presenting Problems}

Grace presented for treatment with several PTSD symptoms, including irritability, intrusive thoughts, flashbacks, anger, and avoidance. She identified these as stemming from the witnessing of her brother's suicide four years before. "Some days it consumes me," she said. "I wish I could erase it." Grace had been repeating a cycle of repressing her affect surrounding the suicide for as long as she could until it overflowed, resulting in her exploding in rage and sobbing. At the time of the suicide, a close relative had added to Grace's sense of horror by saying, "He did it in your room because he hated you the most, he resented you." Due to this, as well as Grace being self-effacing in general, she also presented with a feeling that the suicide was in some way her fault. She felt that she and her family should have somehow done more to prevent it from happening. She expressed frustration that she couldn't "handle" the incident, saying that she didn't feel it was "normal” to be having the reactions that she was.

Grace was motivated to explore her trauma because she felt that her relationship, job, and well-being were being jeopardized by her irritability, anger, inability to relax, and intrusive thoughts. She explained that she was lashing out at her primary source of support, her husband, and she was unhappy about this. She also had a desire to examine what had happened in a more genuine way; she had been experiencing affective meltdowns but had no way of understanding what was happening when these would come on. She described hating the feeling of unsettledness that she so frequently had: a feeling of being antsy and wanting to "jump out of my skin, like I'm going to explode.” In essence, she would either avoid or ruminate, but there wasn't a lot of mindful processing of what she had been through.

\section{Quantitative Assessment}

Late in the third and final phase of treatment, during session number 38, Grace filled out two psychometrically proven quantitative measures as a gauge of where she was "post" intervention. Unfortunately, I did not have these measures at the start of treatment. (In the future, this is something I would incorporate from the start of treatment, in order to get a valid assessment of the patient's state both pre- and post-treatment.) After the 39th (second to last) session, I asked Grace to fill out the two measures as she remembered her state of mind at the start of treatment. Obviously, this is not the standard way of administering these questionnaires. However, I believe there is clinical usefulness to see Grace's subjective measure of her growth and change, especially in the context of the qualitative data about change that existed.

The first measure, the Trauma Symptom Inventory (TSI; Briere, 1995;

http://www.johnbriere.com/tsi.htm), is a 100-item test of posttraumatic stress and other psychological sequelae of traumatic events. It contains three validity scales: Response Level, Atypical Response, and Inconsistency Response; and 10 clinical scales: Anxious Arousal, Depression, Anger/Irritability, Intrusive Experiences, Defensive Avoidance, Dissociation, Sexual 
Concerns, Dysfunctional Sexual Behavior, Impaired Self-reference, and Tension Reduction Behavior. Grace's pre and post scores on the TSI are presented in Table 2. They are presented in terms of "T scores," where 50 represents the mean of the nonclinical sample, and 10 represents the standard deviation of the clinical sample.

As can be seen, at both time points, all three of Grace's validity scales were in the normal range. On the clinical scales Grace's remembered state at intake shows four scores in the 60's (one standard deviation above the norm), and one over 70 (two standard deviations above the norm). The four included: Depression, Anger/Irritability, Impaired Self-Reference, and Tension Reduction Behavior; and the scale over 70, Intrusive Experiences. All of these scales are consistent with Grace's qualitative presentation at intake and the diagnosis of Posttraumatic Stress Disorder that she achieved at intake.

The second measure was the Outcome Questionnaire-45 (OQ-45; Lambert et al., 1996; http://www.oqmeasures.com/site), a 45-item, self-report tracking instrument designed for repeated measurement of multifaceted client progress throughout therapy and at termination. It has a total score and three subscale scores: Symptom Distress, Interpersonal Relations, and Social Role. Grace's pre- and post- scores are presented in Table 3. As can be seen, three of Grace's scores-Total Scores, Symptom Distress and Interpersonal Relations-were above the clinical cut-off, and one, Social Role, was at the clinical cut-off point. Again, these are consistent with the clinical level of Grace's symptoms at intake.

\section{Relevant Personal History}

Grace's relationship with her siblings had at times been a source of tension. She spoke of often trying to fit in with them. She believed there was resentment toward her, especially from her brother, who felt that attention had been taken away from him when she arrived, relegating him to the "middle child" position in the family. Despite her brother being somewhat oppositional and frequently in trouble, she idolized him. She recalled often running after him, wanting to be included, but frequently being disappointed: "I wanted to always be with him, but he didn't want me around."

As they aged and Grace's brother struggled more, she found herself covering for him at times. She was the one who would typically let him in when he arrived home late at night, drunk and vomiting; they would keep this repeated occurrence secret from their parents. At the time of his death, she was angry with him; he had been stealing money from family members and drinking heavily. She said the family had attempted to get him to join Alcoholics Anonymous, to no avail. Grace said, "Maybe we should have forced him (to get treatment)"; we explored this desire together, as well as how realistic an expectation it was.

Within Grace's family, there was a seeming unwillingness to explore the suicide or its aftermath in any detail. She described her father as stoic and her mother as irritable following the incident. She surmised that there was shame at least on her father's part about the suicide. It appeared that Grace's needs for connection, openness, and mutual support within her family 
hadn't consistently been met to a degree before the suicide, and they now continued not to be met, at least when it came to how this event had had an impact on the family. She often saw herself as a caregiver, but was not receiving the care she desired in return.

\section{Presentation at the Beginning of Therapy}

At the start of our work together, Grace was very ingratiating. She appeared to want to please me. She was also unfamiliar with therapy (beyond her one group experience, which had overwhelmed her; see next paragraph for more detail). Grace spoke with pressured speech much of the time in this phase of therapy and was at times circumstantial in her presentation. She would also include many details of the stories she told. I hypothesized at the time that this might be due to her anxiety at being in a new situation as well as an unconscious desire to flood the room with material as a means of avoiding the upsetting imagery at the root of her troubles. While she was committed to being in treatment, this ambivalence is common. Furthermore, Grace was a self-described caregiver; being in the role of someone there to receive support was a new one for her and not one that came easily, even though she would later talk about how she yearned for this at times.

As mentioned above, Grace was new to therapy. She had tried it once prior, in an outpatient group directed at survivors of suicide. The group had upwards of twenty members and Grace came away from the experience feeling overwhelmed by their stories. She did not return. Following this, a close friend who'd had a successful individual therapy experience encouraged Grace to seek out treatment on her own.

At the start of therapy, Grace would miss approximately one session per month due to illness. Just as her psychological defenses were being strained, I hypothesized that her physical defenses were as well. She was often rundown and sick. Interestingly, many studies have been done showing that confronting traumatic memories via writing has led to improved immunity and physical benefits (Esterling et al, 1999; Pennebaker \& Seagal, 1999; Murray, 2002). By the latter part of treatment, this connection had been discussed and her absences were less.

\section{Diagnosis (Table 4)}

As shown in Table 4, at the beginning of treatment, Grace met the DSM-IV criteria for Posttraumatic Stress Disorder (Chronic). Specifically, she had been the first to witness an event involving the violent, self-imposed death of a family member and this event continued to interfere with her functioning years later. Her response had involved helplessness and horror. She continued to re-experience the event via intrusive images and at times found herself triggered by cues that reminded her of it, which caused great distress. She was at times avoidant of any reminders of the event. She was frequently irritable, with outbursts of anger, and often had difficulty concentrating. These reactions were causing some impairment in her relationships. However, it should be noted that while she was impaired at work and at home, she was still functioning relatively well overall. 


\section{Strengths}

Grace's strengths were plentiful. She came to therapy with a willingness to trust and to explore what would prove to be challenging material. She was able to see me as a safe object and form a secure attachment to me. She was motivated to understand what was happening to her and to sort out what at times felt like an overwhelming amount of dysregulated affect. While traumatized and at times paralyzed by her memories of the suicide, she was also hopeful about the future and eager to work through her posttraumatic symptoms, as well as explore the roots of both the suicide and, eventually, her family dynamics, interpersonal style and relational patterns.

In addition, she wanted to gain insight both for her own well-being and for the sake of her relationship with her husband. This relationship appeared to be a strong, authentic, and healthy one, providing support and love. Grace possessed a good deal of ego strength as well as selfawareness. Her personality appeared to be organized at a healthier, neurotic level, as opposed to a borderline or psychotic level (McWilliams, 1994).

\section{CASE FORMULATION AND TREATMENT PLAN}

\section{Formulation}

Grace was conflicted over how to cope with what was the most significant loss in her life, that of her brother. But even prior to this loss, Grace had struggled with feelings of low selfworth and not having her needs met. She had at times been caught-i.e., triangulated-between her brother and parents. In addition, she felt that her siblings at times had feelings of jealousy and resentment toward her. Thus, she at times experienced a scarcity of resources when it came to her family, as if there wasn't enough love and affection to go around. Indeed, Grace also felt a loss when it came to her sister, once saying in therapy she felt like telling her, "(Our brother) abandoned us, now you're going to abandon me?” Grace spoke of her frustration at feeling as if she had to plead for care and attention from her sister.

On the one hand, Grace acknowledged her disappointment in her family: her father's stoicism, her sister's blaming nature, her frustration at her brother for choosing suicide and violating her personal space in the act. However, she had a hard time connecting affectively to these thoughts. So while she may have known these things intellectually, she had yet to make the tie to her feelings of disappointment in her primary attachment figures. She had yet to truly feel her grief as her family was engaging in a collective defensive posture around the suicide. By coming to treatment, Grace was bravely attempting to face the suicide and to begin the process of grieving what she had lost (as well as accepting what she may never have really had, at least in a way that felt emotionally nourishing).

In terms of the object relations and attachment theories that underlie AEDP, it seems that Grace's early family experience did not seem to provide a fully adequate "holding" environment. On the other hand, it appeared that Grace's husband, whom she had known for several years, had 
served as a stable, secure attachment object (Bowlby, 1973, 1980, 1982), and this was a crucial component of Grace's psychological strengths.

Grace's core desires to be accepted, loved, and cared for had also been challenged by the violent departure of her brother. There seemed to be a general avoidance of deeper affect or exploration in the family, which Grace never thought to question before the suicide. It appeared that the brother's devastating suicide rocked Grace's perception of the world as being a safe place. While the others in the family appeared satisfied — at least outwardly - to return to their prior pattern of staying more on the surface and not exploring deeper levels of meaning or affect, the disruption resonated with Grace on another plane. It appeared as if the suicide uncovered the reality that there were unspoken tensions within the family, and Grace was no longer able to abide by an "ignorance is bliss" approach to life.

\section{Treatment Plan and List of Treatment Goals}

Besides being a survivor of trauma, Grace was unfamiliar with therapy and quite anxious. Due to these factors, the initial phase of treatment was used to familiarize her with the process of psychotherapy, develop a strong alliance with the therapist, and start to build her affect tolerance prior to doing any intensive processing of the trauma. The middle phase of treatment incorporated a series of therapeutic writing assignments meant to gradually expose her to the traumatic incident. The third and final phase of treatment served to solidify her gains, celebrate her sense of self, reflect on the deep processing done, and work toward termination.

Among the factors seeming to work in Grace's favor were her ability and willingness to attach to, trust, and take from the therapist; eagerness to overcome her trauma symptoms; a support system outside of therapy; general high level of functioning; and emotional intelligence.

Grace seemed appropriate for the Accelerated Experiential Dynamic Psychotherapy component of treatment in several ways. According to an American Psychological Association description of the model (Fosha, 2006b), "The typical client with whom AEDP has shown to be highly effective is someone who has (a) a history of trauma or loss (b) an ability to function, despite his or her considerable difficulties and (c) some capacity for reflection." Further, the description states that the typical AEDP client is often overly responsible and a "caregiver"_all traits that fit Grace.

As far as the expressive writing component, Grace willingly agreed to try it, although she had concern that she wasn't a "writer" per se. I stressed to her that one did not need to be a writer or even familiar with journaling in order to benefit from expressive writing. I also made clear at this point that it was not analogous to writing for school, i.e., there would be no grading involved, and if it did not feel comfortable to her, she could always opt out of this part of the treatment. She also had some ongoing anxiety about addressing the trauma in such an intensive manner; I monitored this throughout the treatment and made sure to proceed only once she was ready to do so. 
In sum, while Grace did not have a history of childhood abuse, complex PTSD, or dissociative personality features, she was intensely affected by the traumatic event in her history and I intended to proceed thoughtfully and at a pace that felt right to her. Of particular note was the speed at which we were to access the processing of the traumatic material, since avoidance and fear often play a primary role in posttraumatic stress symptoms (van der Hart, Steele, \& Ford, 2000). Due to this, I planned to pace the treatment carefully, so as not to retraumatize Grace or overly exacerbate her symptoms.

I had a series of goals for Grace's treatment, in keeping with the phases of treatment presented in section 3 above in the guiding conception. As mentioned above, while these are presented in order, they were not always linear. Some were being worked on simultaneously, while some would be worked on and then revisited at a later point in time. Movement from one goal to the next was fluid and shifting.

\section{Treatment Goals Overarching All Three Phases}

GOAL 1: To decrease Grace’s irritability and other PTSD-related symptoms.

GOAL 2: To help Grace grieve in a genuine way instead of anxiously describing.

\section{Phase 1 Treatment Goals}

GOAL 3: To establish a genuine attachment with Grace and develop trust and safety.

This goal is especially important in light of the phase-oriented treatment of trauma model (Herman, 1992; van der Hart, Steele, \& Ford, 2000), which says that the first stage ideally involves stabilization and development of safety before any active trauma processing is done. It is also in line with the AEDP goal of establishing an authentic connection between therapist and patient so that shame, defenses, and anxiety can be bypassed and core affect and ultimately core state can be accessed.

GOAL 4a: To slow Grace down so that she could begin to identify a range of feelings and increase her affect tolerance.

GOAL 4b: To work within the AEDP "Triangle of Experience" and go beneath the defense and anxiety points to reach core affect.

GOAL 4c: To challenge Grace’s defenses while maintaining our bond.

Goals 4a-4c are in line with Fosha's goal of "affective competence" (2000). I aimed to identify examples of affect in session to show Grace what her expressions of feeling looked like. In addition to identifying affect such as sadness and anger, I also aimed to focus on mastery and healing affects (Russell \& Fosha, 2008) like gratitude and strength, with the plan of utilizing our psychotherapeutic relationship as a tool to identify examples of these when they occurred in session as well. 
The second part of this goal was to expose the defense and anxiety points of the triangle as "protecting” Grace from her core affects of longing, sadness, and anger. Grace was using a number of defenses to avoid her hidden feelings: rationalization ("They [her parents] did all they could”), idealization of others, avoidance. She also displaced much of her agitation onto her husband by verbally attacking him when she felt overwhelmed, which caused her to then feel regret without dissipating the energy around the true source of her upset. Prior to treatment, she had been repressing what felt like intolerable feelings, but still, they were bubbling up.

I aimed to get beneath Grace's defenses and go beyond some of the manic nature of her repeated flight away from affectively-charged material. She was keeping herself so occupied via obsessional, circular thinking that I knew I'd have to slow her down until she got to a place where she was truly connected with her pain and core affect. I hypothesized that it would likely be difficult for her to relinquish the control that had been self-protective in some ways and knew that I would have to work with her on accepting that she does not ultimately have the control she so desires; life is uncertain. Grace acknowledged that relinquishing control made her "uneasy" and "antsy."

The third part of this goal was to challenge her defenses while maintaining an attachment to me, to have our bond feel solid as opposed to tenuous or conditional.

\section{Phase 2 Treatment Goal}

GOAL 5: To expose Grace to her traumatic memories and work on integrating them into a more linear narrative.

This was to be the focus of the second phase of treatment, which would use expressive writing as a means of exposure and processing the traumatic incident at the heart of Grace's current posttraumatic symptoms. This goal would not be started until there was a sense of trust and safety established between us.

\section{Phase 3 Treatment Goals}

GOAL 6: To increase Grace’s ability to be alone and to claim time and space for herself.

I also knew that it would be important to give Grace a much-needed sense of psychic space, since hers had been invaded by images of her brother's death. She commented early on, "I never know when to give myself space." A goal of the treatment would be to help her become attuned to her needs so that she could start to reclaim this sense of space for herself and more deeply appreciate and enjoy her own company rather than feeling the need to fill every moment with distractions.

GOAL 7: To solidify Grace’s sense of self, i.e., her “self-at-best”or “true self.” 
I planned on working to increase Grace's insight and self-understanding as well as help shore up her sense of self, i.e., help her access her "self-at-best" (Fosha, 2000) more often. This consolidation would be the focus of the third and last phase of treatment.

\section{COURSE OF TREATMENT}

\section{Phase 1: Sessions 1-14}

\section{Sessions 1-4: Introduction to Therapy, Developing Rapport}

From the beginning of treatment, I was mindful of my goal to establish rapport and begin building trust. My goal was to have Grace feel that therapy was a safe space, one in which she could begin to both identify and explore affect that felt overwhelming at times. In these early sessions, time was taken to familiarize Grace with therapy and to provide some psychoeducation, both about the process of psychotherapy and also about posttraumatic reactions. I especially wanted to establish a sense of safety due to the trauma that Grace had been through. While patients should feel safe in any therapeutic relationship, trauma survivors in particular may have a more difficult time trusting others and feeling safe.

Also from the start, I was mindful of the tenets of AEDP and strived to be authentic and present in the treatment. According to Fosha, the AEDP therapist is "explicitly empathic, affirming, mutual (though asymmetric), affect regulating and engaged emotionally” (2007, p.2). With this description as my guide, I eschewed a more traditional analytic stance of neutrality (which is not my typical way of working anyway) and was explicitly engaged and empathic both verbally and nonverbally.

In the early sessions, I gathered a detailed history and began to assess Grace, in terms of her symptomatology but also her personality style and interpersonal and ego functioning. I began to formulate her attachment style and who may have served as secure objects for her, both in the past and the present.

Grace's style and presentation in these sessions were pressured. At this early point, I tended to listen more as opposed to interjecting, while using nonverbals like steady eye contact, engaged facial expressions and body language to convey that I was paying attention. After the first couple of sessions, I said, "I may stop you at times to ask how you're feeling as you tell me something, or to slow you down a bit so we can explore what's happening in a deeper way." Grace responded favorably to this, and from that point forward, it became easier for me to pause her.

During this time, I introduced the idea that the treatment would continue for as long or as short a time as felt helpful to her. I suggested beginning with a goal of 20-24 sessions, which, if seeing each other on a weekly basis, would take about five to six months (this was per the shortterm model that I was planning on adhering to for the class I was taking). Grace expressed relief at this idea, saying that she was glad to have some time to work toward processing the suicide 
instead of diving right in. This was in keeping with my plan of a phase-oriented model, which stresses the need for stabilization and safety before active trauma processing begins. (At the time, I was unsure about putting an artificial ending on the treatment, but this was required by the class. We were able to revisit this idea at a later point, and ended up surpassing the May end date by another seven months.)

In this early phase we also began to explore Grace's guilt about not doing more to prevent the suicide, as well as her fear that she was somehow responsible for it, per her relative's comment that he had done it in her room because he "hated her the most." (We would later discover and discuss potential other reasons for him choosing this space, including that it had originally been his bedroom, and that he had continued to feel an attachment to and ownership over this room.) Again, I provided psychoeducation about the posttraumatic symptoms Grace was experiencing, without yet labeling it as Posttraumatic Stress Disorder. I wanted to work with Grace’s fear that she wasn't "normal” for having these symptoms by normalizing not the horrific incident itself, but her horrified reaction to it.

Along these lines, Grace began to discuss her desire to have control in all situations, to "plan everything out." She stated, "I hate not knowing what's going on"; this made her feel like she wanted to "jump out of her skin.” Grace talked about how she had started to "overanalyze” in the last few years: "I have to get to the bottom of things." While she had always been organized, this desire for control and style of hyperanalysis had become more pronounced following the suicide; Grace told me that before the suicide, "I used to go with the flow." The uneasy and antsy feeling had become more frequent and was one of the things that had led Grace to pursue therapy. I began to hypothesize that Grace's attempts to keep everything under control was her way of "dealing without feeling” (in line with Fosha's concept), keeping everything bottled up until it would then snowball and result in the wanting to jump out of her skin feeling, in which her affect would flood and overwhelm her (in line with Fosha's "feeling without dealing” concept).

Grace also began to approach sad affect in this phase, although she couched her tearfulness with statements like, "I hate getting upset, I've cried so much.” For her, affect was associated with feeling awful and out of control. I worked to both validate the underlying affect while also exploring with her the possibility that this pure expression of emotion didn't have to feel so out of control and disturbing. My goal was to have her begin to access a range of affect in a more organic way while feeling supported and contained within the therapy relationship. However, it was striking that even in this early phase, Grace possessed the ability for honest selfexamination and the labeling of her affect, e.g., "I’ve been sad lately thinking about (my brother). I don't have him anymore and I was starting to get closer to him.” Following this statement, she was then able to describe how she had always wanted to be with him, even when he didn't want her tagging along. Grace's thoughtfulness and ability to connect affect with unmet needs and desires bode well for a successful treatment.

Grace's caretaking nature also began to come to light in this phase. In session \#4, she commented, "I always want to take care of everyone else." I began to formulate that this desire, 
while genuine, may also be at least partially rooted in a reaction formation of sorts: there appeared to be a good deal of anger and disappointment that Grace had a hard time accessing. My aim was to work with Grace to access her desire not just to take care of others, but for them to take care of her. Interestingly, Grace appeared to be taken care of by her husband, but it was hard for her to genuinely accept and absorb his nurturing.

In the spirit of AEDP, I would often share my thoughts with Grace. I aimed to establish an open communication in the therapy, and to be transparent in my thoughts, feelings, and reactions. Especially because she was a survivor of trauma, I was cognizant about the importance of honesty in the treatment, as a way to establish a genuine connection and trust. I did not want for her to ever feel shocked or blindsided about a direction the treatment was taking.

Sessions 5-10: Firming the Therapy Relationship, Building Trust, Accessing and Normalizing Affect, Getting Closer to Processing the Identified Trauma

In session \#5, Grace stated, “I don’t feel selfish making myself a focus...I've made others the focus for too long." This felt like an assertion of her ability to nurture and value herself, as opposed to consistently putting others first. To be able to state this so clearly so early in treatment was a positive sign, as I saw it, and I verbally identified these statements for her.

The following week, in session \#6, Grace commented, "I’m really proud of myself." This was a shift from the style of downplaying strengths that she had presented more consistently to this point. Referencing this statement, Grace said that she wasn't used to saying things like this out loud, because she would never want to come across as "conceited." In an attempt to further accentuate Grace's true self and strengths, I wondered aloud with her about the roots of this concern. This discrepancy between how Grace actually felt about herself versus what she would share with others would be an ongoing theme of our treatment. It followed the AEDP goal of "affective mastery," which includes "the undoing of shame and the emergence of pride and pleasure in the expansive, competent self” (Fosha, 2007), as well as the subsequent relishing of that self.

Another ongoing focus of therapy was Grace’s relationship with her family. In session \#5, she said, "I'm on the outside, I do things differently." This was in reference to the fact that she wanted to talk about her feelings, which was a contrast to her sister and parents. At this point, Grace was often focused on how she could be of help to the rest of her family; indeed, this was a goal of hers: "I want to get myself good so I can help (my mom) through things." Thus, she was still looking at her own wellness as a means to support her family. It was difficult for her to fully embrace doing something just for herself. By the end of this phase of treatment, Grace would begin to differentiate from her family more. She recognized that her desire to process the suicide and understand the resultant emotions and reactions was not shared by the other members of her immediate family and she was beginning to see this as okay, whereas when she had first come in, there had been a stronger desire to join with the family. 
In particular, Grace's relationship with her sister was becoming a point of focus. Grace was recognizing the expectations she had of her sister that were going unmet. She would often voice this frustration, e.g., "Why can't she be happy for me?” I would at times ask Grace to speak to her sister as if she was in the room, addressing her directly. Together, we began to tease apart what she truly desired versus what she could realistically hope for from her sister, at least at this point. It became apparent that Grace was not only attempting to grieve her brother, but also to grieve her relationship with her remaining sibling.

In session \#7, Grace said, “I hope you don’t think I’m crazy, talking about other things when I came in to talk about my brother.” I wanted to both understand where statements like this were coming from and also continue providing psychoeducation about the process of psychotherapy. Because Grace was new to therapy, she was operating on an assumption that she was only "allowed” to discuss the suicide. While I was aware that not discussing it at times could be the result of avoidance, I also wanted Grace to feel free to bring in whatever topics were on her mind. In addition, it felt that a lot of the material being presented was related to the suicide, even if not directly. Grace was talking more about her position within the family as well as patterns of relating (or not relating) that were embedded in the family system. With each week, I felt as if I was getting another page out of the family's history and that the story was coming together.

Grace was also beginning to access her affect in a more genuine way and not run from it. We were starting to talk more about the suicide and her relationship with her brother, without yet processing it deeply. In session \#8, she commented, “Getting upset here is good. I don’t feel as uptight, frazzled or edgy. I feel relieved.” Continuing in a relational mode-following the AEDP approach and also in order to continue to establish safety-I began stating that she wasn't alone when she accessed this affect, she was there with me.

Grace said at this point that she trusted me and that this made it easier for her to approach the previously guarded-against affect. Interestingly, it was around this time that Grace began to ask more questions about me, e.g., “Are you a student here?” When I told her that I was, she said that I must have a tough schedule and that she would "bring some snacks for us one night” to enjoy (while this became an ongoing point of reference, no actual food was ever exchanged). Grace was then quick to say, "I'm not trying to pry," as if she was worried that her inquiries would broach boundaries. In line with the tenets of AEDP and other relationallyoriented therapies which emphasize that the therapist should be an authentic and present member of the dyad, I answered Grace's questions straightforwardly as well as wondering aloud about them with her. I did find it interesting that she was joining with me and wanting to soothe us with snacks.

Along these lines, Grace spoke of wanting to eventually be of help to other survivors of suicide, but added, "I need to fix myself first." She then commented that her husband told her that she should be a therapist. I explored this desire to take the focus off of her own healing by asking, "How is it to come here and I do (most of) the listening?" She said, "It feels good to let go, but it feels like I should be on your end." 
In session \#10, Grace discussed in more detail the meltdowns she was still having out of session, which sounded like dysregulated affect states that she was unable to soothe herself out of. She described getting so angry and upset that, "It scares me. My head hurts, my heart's pounding, my chest hurts...it's like someone dropped a thousand pounds on me and I can't get out from underneath it," which I verbally likened to the metaphorical weight she carried on her shoulders. In session, I had begun to ask her to identify how she felt things physically as well as emotionally; this somatic focus is part of AEDP (Fosha, 2000) as well as trauma treatment (van der Kolk, 1994). It is a means of increasing mindfulness as well as further integrating how a patient experiences him or herself in the world, of bringing together affective, somatic, cognitive, and relational states.

At this point in the treatment, Grace was beginning to approach a more authentic grieving for her brother. In session \#10, she was able to say, "I just miss him so much...it was so sudden, I wish I could have said something to him before"-while indicating that she was connected to a deep sense of sadness and grief.

\section{Sessions 11-14: Ambivalence about the Therapy Comes to Light}

Following the particularly affect-focused and more intense session \#10, there were a few weeks where it felt to me that Grace was more defended and avoidant of approaching or staying with deeper affect. She was in the middle of a big move which was keeping her preoccupied, and I wondered if she was attempting to squash the affect which we had begun to access; to put the scab back on the wound, so to speak. She said as much in session: "(The move is) keeping me so busy, I don't think about (my brother). It helps, but it sets me back, too.” I validated that moving is indeed a stressor, and that it was okay for us to proceed at whatever speed felt right to her. (I wonder now if I should have explored the "it sets me back" part of her statement even further. In light of us beginning to touch upon deeper affect and portions of her trauma as well as her spoken desire to be in the therapist seat as opposed to patient, I probably should have.)

Not surprisingly, Grace began to share how it was at times difficult for her to come to therapy: "I know I should come, I know I have to come." She would then be quick to reassure me, "I still wanted to come." She likened therapy to helping her put the pieces of her life together, pieces that "felt broken before." At the end of session \#11, she commented, "I feel like I can’t put things together myself right now so I want your help.”

A few weeks later in session \#13, Grace spoke of a lot coming up at work and wondered if she should switch her sessions to every other week. She was honest about her struggle with therapy. She said that it was "draining” and that she was "torn," but that on the other hand her best friend had told her, "You think you're ready (to go less often), but you're not." Internally, as her therapist, I struggled with this as well, since I felt as if we were on the cusp of some deeper processing of Grace's core trauma, as well as doing a lot of intensive work around interpersonal, identity, and affective issues. But I also felt it was important to allow her to feel agency around decisions like this. 
Interestingly, later in session \#13, Grace spoke of how she was feeling calmer in general. When I inquired about what was helping her to feel more calm, she said, "When you would stop me and make me realize why I'm feeling a certain way. Now I can stop myself and ask, 'What am I really upset about?'” Thus, despite her ambivalence about coming to therapy, it also felt as if she was starting to internalize my voice and the therapy and beginning to examine what might be happening when she was triggered out of session.

Also in this same session, Grace brought up a fight she'd recently had with her husband during which she felt he hadn't been listening to her. Grace said, “It was almost like I didn’t exist...I felt alone." We examined this, and why it had felt so hurtful for her. After we processed this experience, Grace said, "I know I should stay every week. I'm coming here for me. It's not just one more thing I have to do.” I later hypothesized that perhaps a part of her had been "heard" by me in the treatment once she was able to speak more freely about its challenges and how some weeks she really didn't feel like delving. Similar to her desire to be seen and heard by her husband, I wondered if she had needed a clearer affirmation from me that I was listening and respecting her needs and desires, including her fear of accessing painful memories.

Following up on this the next week, in session \#14, Grace spoke about her dedication to therapy and that she not only "should" be doing it, she "wanted" to. Interestingly, she had been feeling sick in the days before with a sore throat, which in the past would likely have kept her home, but she made it in.

In this session, we talked more in depth about her brother and the aftermath of the suicide, during which Grace continued to live in her bedroom. She spoke of lying in bed, looking at the doorway and thinking, "That's where it happened." She spoke of that night and seeing her brother's body on the floor after he had been taken down. These images had not yet been shared in therapy, and Grace was able to access affect around them. Following is an exchange from this session in which I followed Fosha's concept of undoing "unbearable aloneness" via affirming my willingness to be there with Grace as she discussed painful imagery:

Erica: Try and go back there little by little with me. You're holding onto this and I think part of the reason why it's so upsetting is because you had to deal with a lot of this by yourself. It happened in your room, and you went back and lived in that room. You have all these images in your head that have been locked away...we will access this at whatever speed feels comfortable. I want to keep checking in, and if it starts to feel scary or overwhelming, tell me.

Grace: It is scary....it would be easier if I didn't see it.

Erica: You saw a lot.

Grace: Too much.

Erica: You did-you saw more than anyone should ever have to see... and you dealt with a lot of this alone. You saw a lot of this alone. You're not alone with me. 
I asked Grace if it would be okay for us to talk more about her brother, explaining more about PTSD and frozen memories of traumatic incidents and the importance of trying to integrate and form a narrative out of these memories. Grace said that the prospect of doing this was scary, saying, "I'm on board with doing it, but I'm not looking forward to feeling sad again.” I took time to validate her fear, to remind her that she could always tell me if she was feeling overwhelmed and we would stop, and to again assert my presence in the room and in the relationship. I also made sure to reinforce the idea that she'd already done a lot of good work in therapy and made progress, and that this wouldn't be negated.

At this point, Grace told me, "I want to put the story together and close the book." Taking this as a cue and feeling like we had turned a page (so to speak), I suggested we start the writing component of the treatment (we had discussed journaling prior to this, as well as the idea of writing as a way Grace might eventually be able to address more difficult memories). While Grace was slowing down more and more, there was still a feeling at times that her presentation was rushed. My aim remained to have her do some more genuine grieving as opposed to anxious discharging, and I planned to utilize writing as a means to help us get there together. I also thought that the writing might be a means to further develop and strengthen Grace's voice.

By this point in the treatment, with my encouragement, Grace had started to carve out time for rejuvenating activities like going to a bookstore and spending an hour looking through books. To slow herself down in this way and take time to do something for enjoyment and recharging was atypical for Grace. She relished this new experience. I marked it as a stepping stone toward the treatment goals I'd set of self-discovery, self-knowledge, and the ability to appreciate solitude.

\section{Phase 2: Sessions 15-29}

\section{Sessions 14-15: Introduction of the Writing and the First Completed Assignment}

I began Phase 2 by introducing Grace to the writing assignments in session \#14. I gave her the first assignment the following week, in session \#15, which was to "Write About a Childhood Memory." This exercise was to be completed for and read aloud in session \#16. The various subsequent writing assignments employed are presented in Table 5.

In introducing the writing component of the treatment, I discussed with Grace how I saw it unfolding. The aim was to eventually write about the traumatic incident itself, but I intended to familiarize her with the process of writing for several sessions before this. I had multiple goals for the writing beyond using it as a means of exposure (via having Grace write in detail about the selected trauma). I also aimed to have her (1) become more comfortable taking time for herself (while writing); (2) further develop and solidify her own voice and identity as well as tap into Fosha's ideas of the self at best and core state; and (3) further get in touch with aspects of herself and her history that weren't related to the suicide, since memories of the event had clouded her psychic space in recent years. 
Before Grace began writing, I discussed the guidelines with her. I suggested she find a comfortable spot in which to do the writing each week, one where she felt relaxed. Pennebaker (2004) speaks about how places, time, and atmosphere can be quite meaningful when it comes to writing. He also talks about a "flip-out rule" (2004), i.e., a person should stop writing if the feelings become too overwhelming. With this in mind, I advised Grace to stop writing if she became overly flooded; she could always come back to it at another point. The plan was for her to then bring the writing into session and read it aloud each week. The reasoning for this was to deepen the processing; it was also in line with both the relational aspect of treatment and work with trauma patients (Resick 2001, 2007). Often, trauma survivors feel alone with their traumatic history. The goal of Grace reading her writings aloud to me was to provide a witness to what she had seen. While we couldn't change the way the trauma itself had unfolded, we could impact how alone Grace felt moving forward.

I also encouraged Grace to attempt to tap into all of her senses when writing, to try and make the images come to life on the page. I told her that not only was she a character in her story; she was also the author. I urged her to be mindful of how she was feeling as she wrote and to make note of any affect that came up. Finally, I encouraged her to be free with her writings and not to focus on spelling or grammar; this was not a school assignment. Above all, I wanted to continue to prioritize the safety that had been so important to establish in our treatment.

I should mention that while the writing activities became an integral part of the treatment, they were not always the focus of sessions (although they often served as a springboard to important areas and deeper exploration). Generally the writings that Grace did were of a length that each took under 10 minutes to read in session (although the writings directly about the index trauma were longer and took up to 15-20 minutes to read, with pauses; discussion of them also took up larger portions of their sessions). I remained flexible in the application of the writings and used them as a tool to enhance Grace's process and therapeutic growth as opposed to following them as if from a manual. The only concrete writing goal I had was to eventually spend multiple sessions on the index trauma of the suicide (once the writing felt more organic to Grace). Otherwise, I worked on developing writings that felt reflective of who Grace was and where she was at that point in time. Of course, there was also a purpose to each assignment, but I did not have each of them mapped out beforehand way in advance, as a manualized treatment would. In other words, with the exception of some key assignments which would likely be given no matter the patient, I wanted to tailor the writings to Grace as much as possible, using sources like the journaling therapy work of Kathleen Adams (1990, 2007) as a guide.

Grace bought a new journal for the purpose of the writing exercises. She chose a comfortable chair in her home and began calling it "Grace's corner;" this was where she typically wrote. After a few weeks, she said that she enjoyed the writing and that it enabled her to take time for herself in a way she had not before. During this time, the therapy seemed to deepen. Processing of affect was more consistent, and Grace's ability to spontaneously present with authentic affect was notable. My supervisor and I wondered if the writing and processing that was happening out of session was helping Grace go to deeper places in session. In line with AEDP, we also hypothesized that the writing was accelerating the processing, encouraging deep 
reflection and accessing of core affect. By enabling Grace to connect in a deeper way to her voice, we were facilitating true healing and the accessing of her "self at best" (Fosha, 2000). (Note that since Grace wrote in her journal, I did not have my own paper copy of what she wrote, although I did have the DVD recording of each session in which she read one.)

Eventually, Grace expressed that the writing was helping to organize her, saying she felt less scattered. By session \#19, Grace said that writing felt like a "release," and that it was helping her to have a "better idea why I'm getting stressed." Thus, it appeared that the writing was both helping her to put things in perspective and increasing her self-awareness. See Table $\# 5$ at the end of the document for a list of the writing assignments.

Sessions 15-23: Writing Begins, Deeper Trauma Processing and Exploration of Core Affect, Further Solidifying of Self

Session \#15, in which the first writing assignment was given, followed a session of intensive processing around the suicide's aftermath. Grace expressed that she'd felt sad following that session, but also relieved. We did not do any deep processing in this session, and Grace commented that it felt good not to talk so intensively about the trauma or her family every week, since it was exhausting. She acknowledged that she knew it was "good for" her, but that there were times that she wanted to focus on things that didn’t feel so wrenching.

With this in mind and in the relational vein of our treatment, I explored how she was feeling in general sitting with me. She answered, "It took me a while to feel comfortable, but in the past month or so, I feel at home. I feel like you understand where I'm coming from and (are) helping me to understand where I'm coming from. It's definitely appreciated.” In line with AEDP, I let her know that I was appreciative of her and the work we were doing together as well. A month or so later, in session \#19, Grace would express her gratitude in an even deeper way: "I don't know what I would do if I didn't come here. It's been so hard for me the past few years and this is the first time I'm getting through it." Using AEDP's focus on healing affect, I took advantage of these occurrences as opportunities to stay with the gratitude and explore what it meant: to her, to me, and to us (Russell \& Fosha, 2008).

As mentioned, in this session (\#15), I gave Grace the first writing assignment, which was to write about a childhood memory. I asked her to identify a memory and then try and put herself back there, including how she remembered experiencing it from as many senses as she could — what it looked like, sounded like, smelled like, etc. With this exercise, I intended to begin familiarizing Grace with the process of writing and spending time with herself in this way. I also wanted to encourage her to recall authentic, pure parts of herself, and rediscovering an early memory was a way to do this.

In session \#16, Grace read her entry aloud in session. She wrote about watching the glow of the fireflies, smelling tomatoes from the garden and freshly-cut grass, hearing the insects buzzing, running barefoot and feeling the grass beneath her feet. Grace said that when she wrote, she felt like she was back there, in a story or a movie. "You're a character in your own 
story, your own movie,” I commented. "You're writing your own story.” Grace said that she had enjoyed the writing and having time to herself.

Around this time, we discussed how the therapy space was hers to explore different aspects of herself - desires, feelings, thoughts, relationships-and in which she could safely feel vulnerable. Grace said, “I can let go in here...I like it here, I don't do it anywhere else, but this is my time to feel what I really feel, my own place to go." Increasingly, and despite the level of trauma processing and affect exploration getting deeper, Grace was succeeding at using the therapy room as a safe space.

Importantly, during this phase of treatment, Grace began to talk about how she felt as if she and her husband were acting like a "team" again. "Before it was a vicious cycle, now it's a good cycle," she noted at one point, meaning that now they influenced each other in a more productive and nurturing way and helped each other when one was struggling with something. Grace was allowing him into her emotional life in a deeper way, as opposed to lashing out when she was agitated. It appeared that not only was Grace's ability to communicate clearly and deeply with me in session growing, it was translating to out of session as well. A few weeks later, in session \#19, Grace commented, "If I get upset about something, I'll try to figure out what I'm upset about and be upset with that and not take it out on (my husband) because he's right there, the person I'm closest to." In later sessions, she would repeat these sentiments, i.e., "We know how to take care of each other." Thus, she was seeing the relationship as more of a mutual one, where they both provided and also accepted support from the other. Grace's attachment to her husband was becoming an even more stable, solid, and secure one, and she was now more able to absorb the support and love he provided.

In session \#17, which due to scheduling, fell just a few days after \#16, Grace said that she hadn't done the writing for that week. I shared that I understood (I'd asked her to write a letter to a friend she was having a hard time with, but we had spent a good deal of the session talking about this and Grace felt she didn't have much else to say on the topic). However, I took this opportunity to talk more about the goal of the writing overall and to check in with Grace about her interest in and commitment to it. Grace remembered what I had said about eventually writing more about her brother and the suicide, and that a goal was for her to create a whole narrative as opposed to disjointed fragments. She expressed trepidation about eventually writing about the suicide, saying that she wasn't looking forward to "having to replay it...I hate the situation. But it happened."

This led to some intensive processing of Grace’s grief. She spoke of how her brother was gone, and how "so many times I want to share my life with him...so many things I can change, this is something I can't change. I can't erase it...I think that's the hardest part.” We stayed with this sentiment for a while. When I queried about what she was feeling in her body (per the somatic focus of AEDP), Grace was able to locate tension “...in my chest, when I swallow. It's a ball, a knot, tense, strained.” Grace brought up her family and said that she wanted to be "strong" around them, that none of them had these reactions, as far as she knew. She once again feared that "I'm going to be seen as more of the outsider." I attempted to validate her sensitivity 
and willingness to do this processing, and suggested that perhaps by doing the work together in session, it freed her up to be less overwhelmed out of session.

This felt like a natural step in getting closer to the plan to more directly examine the suicide. Grace was honestly exploring her hesitation instead of shutting down completely or numbing. Despite this hesitation, Grace was increasingly able to put words to her feelings about the event. She spoke of how not knowing why her brother had committed suicide was a "mindwrecking thing," how this was at the root of why she couldn't stand ambiguous situations and not knowing what would happen.

Due to Grace's hesitation to write about the suicide, I wanted to reassert that I was listening to her:

Erica: I hear you...I'm not going to abandon you. I'm not going to push you when I sense that you're really struggling, that's not what this is about. You are the driver of this.

Grace: I appreciate that. I definitely feel comfortable. I know I can say I don’t know if I can go into this right now.

Grace commented how at the start of therapy, she had expected me to tell her exactly what to do to feel better. She now understood why I hadn't done that, and why that wasn't necessarily possible anyway. "There are ways I look at things now that I would never have seen before,” she said. I took Grace’s ability to speak about her early disappointment with me and the therapy as a good sign that she now felt she could be honest, especially in light of her selfdescribed "caregiver" status. She was able to take a risk by saying she had been nervous that I might not be able to help her.

At the end of this session, I took the time to check in with Grace:

Grace: Tonight's the first night I truly felt comfortable really letting it all out. I felt more at ease.

Erica: What felt different tonight?

Grace: I guess how you reiterated, “I’m here, it’s a safe place, if you have a feeling, you can let it out."

Erica: What can I do to help you through it, to help you continue to feel safe?

Grace: Just by what you said, I know you've said it before. You make me feel comfortable. I'm thankful for it. It's a part of myself that I don't show that often in front of a lot of people, so it's kinda hard. I appreciate it.

Thus it appeared that Grace was taking in my presence and beginning to feel safer in session with me. She was hearing me when I said that I did not intend to pressure or retraumatize her, that I wanted to move at a speed that felt comfortable to her. This validated my 
decision to wait to start the writing component of the treatment until this point. For the next session, as a way of beginning to approach more sensitive topics, I asked Grace to write about a good memory of herself with her brother. I thought it was important to explore their relationship from different angles, and not just through the lens of the suicide.

In session \#18, Grace read the writing she'd done about a good memory she had of her brother. She spoke of a time they'd spent together at a barbeque and how he had been looking after her because she had had more alcoholic drinks than she was accustomed to. Grace recalled that him looking after her was a unique occurrence and remembered wondering, "Why can't it always be like this?" In session, she recalled that while writing, she'd felt a mixture of sadness and contentment. She enjoyed having the opportunity to write about a positive memory, since so many of her memories of her brother were sad or felt tainted in some way. But she also missed him as she thought about it. I reflected back to Grace her ability to hold onto varied emotions simultaneously. For the next writing assignment, I asked her to write about herself in the months before the suicide. My aim was to have Grace refresh her memory of who she had been prior to the trauma.

In session \#19, Grace read about who she'd been in the months prior to the suicide. She recalled feeling carefree and confident. Sessions \#19 and 20 in particular were notable for the presence of healing affect and consolidation of the self that was emerging. I took time to celebrate and validate what Grace was presenting. It felt as if these two sessions were prime examples of the expression of Grace's "self-at-best” or "true self” (Fosha, 2000, 2002b). Grace made several comments during these sessions along these lines: "I feel more comfortable with myself now...I feel like I'm becoming more my own person.” "I'm setting my limits.” "I feel solid, I know myself more.” This emergence and flourishing of Grace's true self felt strong and authentic, as opposed to a more "false self," brittle proclamation that "I'm fine!" It appeared that she was getting better at setting boundaries with others as well as knowing and valuing herself in a deeper way. Grace also shared that she was starting to not force herself beyond what she felt were her limits. She was learning how to listen to the signals of both her body and her mind, and it was becoming okay to adhere to her needs as opposed to pushing herself to fit someone else's mold or demands. She contrasted this with how she had been less confident and valuing of herself in the past.

Grace's confidence in her ability to handle both affect and ambiguity was growing, as uncomfortable as she felt with it at times. She commented that she felt like she wasn't "just reacting” to things anymore; she felt calmer in general.

In session \#20, Grace read aloud her writing about a more challenging memory she had of her brother. This led to some deep processing of her grief and bereavement. She commented, "I can't believe my brother killed himself." This was one of the first times she spoke so candidly about her disbelief that this horrific thing had occurred, using this specific terminology, i.e., "killed himself" as opposed to something more euphemistic. Soon after this in the same session, she said, "I really miss him but have hope toward the future...I have to accept it, I want to, it's 
the truth.” She was again able to simultaneously hold diverse affect — to feel upset but also acknowledge hope for the future.

In this session, prompted by the writing she'd done, Grace began to talk about how her brother had been disappointing at times. She recounted an incident in which he was so intoxicated-incoherent, eyes glazed - that it felt to Grace like he was already gone, an eerie premonition of what was to come. She spoke of how upsetting it had been to see him in a state like this. She also spoke about his funeral during this session, what it had been like to be there. Grace was tearfully able to say, "I wish he were right here, I want to hug him so bad."

She commented that she was glad she'd been the first to find him, before her parents. I commented that this was honorable, her wanting to protect them in this way, and that I was there to help protect her. I wondered if Grace's protecting, while genuine, was also defensive, in that it allowed her to distance herself from what she had been feeling when she'd found her brother. I didn't bring this up at the time, however, since in this session Grace was doing a beautiful job of remaining connected to deep, core affect. Overall, her growing ability to talk more freely about her brother was remarkable. Wanting to continue this dialogue, I asked her to write a letter to her brother for the next session.

In session \#21, Grace read aloud the letter she'd written to her brother: "I wanted to be a good sister. I didn't make myself be born to make you miserable...I wanted your love, I never wanted it to be a competition where I got our parents to like me better." This was a difficult session for Grace, and at the end I decided to provide a more containing writing assignment. I asked her to come up with two lists: one of the stressors in her life and one of the things that soothed her. In the following session (\#22), Grace told me she had enjoyed making these lists because it made her realize what she really valued and also the sources of stress in her life.

Grace spoke at length in this session about how she felt she was "becoming my own person.” In response to this, I suggested she write about where she was now versus where she had been prior to treatment, i.e. to use the writing to further celebrate this uncovered self.

In session \#23, in response to this assignment, Grace spoke of the past being "overwhelming” and that at times she had felt like she was “drowning." She felt deep empathy toward herself as she recounted this, saying, "I can’t believe I had to go through that...I lost myself. I was dealing with an avalanche.” Grace said it had been somewhat hard to write good things about herself because of her fear that she would be considered cocky, but that she ended up feeling grateful for the assignment. She wrote of herself as a "passionate person with a big heart" and that in the past, she had been so "engulfed" it was hard to take in praise from others. She was slowly becoming more able to take in positive comments, and recognizing what had been getting in her way.

We also talked during this time about extending the treatment beyond May, agreeing to check in every few months about where she was. We agreed to work together through the summer and then see how she felt. 
In session \#23, we were poised to begin the writings directly about the suicide. I spent time with Grace discussing this shift and exploring any anticipation and anxiety she was having. She affirmed that she wanted to move forward. I again encouraged her to think of herself as the author of her story. For the next writing, I asked her to write about the events of the night of the suicide from a third person perspective; the next step would be to transition into a first person viewpoint. The third person point of view was to provide some distance before she tackled a direct account of what she had seen. I spent time talking about safety, including the visualization of a safe place we had talked about in a past session. I wanted to draw a boundary around the activity of writing about the suicide so as not to flood Grace at a time when she was on her own. I made it clear that she should put the writing away if she began to feel overstimulated. We had time to process all of this together in session.

\section{Sessions 24-29: Direct Processing of the Index Trauma}

In session \#24, we processed the suicide more directly than we had to date. Grace had been assigned the following task at the end of session \#23: "Write abut the suicide from a third person perspective" (see Table 5). Grace began the session by saying, "This was probably the hardest thing I've ever had to do but I'm glad I did it." She said she had left the writing for the night before our session so that she wouldn't have to wait long to discuss it with me. The aftereffects were that Grace felt spent but relieved.

Grace described the setting in which she had chosen to do the writing. She lit a fire outside in the backyard, and for this assignment, had her husband stay nearby. She said that she wanted to establish a calming setting, along the lines of what we had talked about in terms of feeling safe. She said that she did stop a couple of times to collect herself, during which her husband would rub her back; "He was perfect," she said. Grace said that she didn't stop for very long each time - a couple of minutes-because she was "already in the moment” and wanted to finish.

The writing itself shifted perspective from third to first person quite a bit. Grace was tearful for parts of the reading. She described the upsetting sensations of seeing her brother so "helpless," of the deep shock, sadness and fear she'd felt in the wake of what had happened. In reading it to me, Grace said that she felt less fear than she had before she'd started to write it. We discussed how she still felt sorrow, but also "more prepared, not as shocked." I talked with her about how she was becoming more conditioned to the material and more able to look at it without feeling dysregulated. I also pointed out that we were now attempting to look at the event from start to finish, in order to create a narrative, and not just in fragmented glimpses.

While writing, Grace said that there were points during which she felt like she was back there and during these times she felt scared, overwhelmed, and lost. It was at these points that her husband rubbed her back and told her that he loved her. Grace gave the writing to him to read when she was finished and he subsequently told her he hadn't realized everything she'd seen that night. For the first time, Grace had chosen to retell the story of what had happened in a more linear fashion as opposed to being triggered and overwhelmed by flashes of imagery that 
felt disturbing, frightening, and not attached to a deeper narrative. She was working to gain control of her story and when and to whom she told it, instead of being overwhelmed by images that snuck up on her.

I spent ample time this session processing the relational aspects of what had transpired. I remarked that she had come to the session, knowing how difficult it might be. Grace said she had considered not coming but had told herself that she would only be putting off something she felt was important to do. I reiterated with her how hard she was working, and how difficult this must be. I also told her again that she truly was "the author of (her) story.” Grace discussed feeling relieved and happy that I gave her "feedback” which felt "rewarding." She again said, "I feel safe and comfortable here...I really appreciate everything." I shared how impressed I was that she had surrendered her former need for control in order to completely immerse herself in this challenging activity and then come to session ready to further process it. I shared that I appreciated her ability to trust in me and the therapy. Grace said that she felt "calmer" after reading the entry aloud to me.

I also asked how she was feeling toward me for having her do this. "I still like you," Grace said with a smile. In keeping with Grace's prior statements about us having snacks together, she said with a laugh, "I should tell (my husband), 'Erica got me ice cream tonight."' Grace offered this up as a joke (we never actually had food in our sessions), but there also seemed to be underlying meaning. (Later, in supervision, I would hypothesize that this might have been her way of expressing that she needed more nurturing or soothing from me after asking her to do this writing. Or, it could have been a way of bonding with me and lightening the tone of the session. It also could have been an expression of her mixed feelings toward me for initiating what had felt wrenching and challenging at times; I would not have been surprised if there was at least some anger toward me. Interestingly, at the end of this session, I did have a desire to somehow comfort her in a more tangible way than I had to date, not with ice cream, but perhaps by giving her a hug. I felt protective. I discussed this further in supervision as potentially being a combination of genuine concern, perhaps maternal in nature, and a reaction to her indirectly expressing a desire for comfort and nurturing from me (via me buying her ice cream). It also could have been a reaction on my part to her potential anger and irritation toward me. It would have been interesting to pursue this more than I did at the time.)

Grace expressed that she was not yet ready to write about the suicide purely from a first person perspective (in the prior writing, while the assignment had been to write from a third person perspective, she had naturally shifted perspective back and forth between third and first). I chose to assign a free write for the following week, in which Grace could choose her subject, mentioning that we would likely return to the suicide via writing at a point in the near future. (I wasn't sure if we would lose momentum or if it was okay to downshift so I brought this up in supervision. My supervisor supported the decision and validated my sense of not wanting to flood Grace, especially in light of Grace telling me she appreciated that I was flexible with the writing assignments and that I didn’t “scold” her when she missed a week. Overall, she was doing the writings consistently, and so I felt flexibility was more important therapeutically than rigidity.) 
Concerning my own reaction to this more intense and graphic material, my stomach was upset at times during the session, almost in anticipation of hearing the details. Following the session, I had a headache and took a long walk outdoors in order to center myself. This, along with the support of supervision, was helpful in keeping me grounded and available to Grace.

In the next session (\#25), I expected to do some follow up from the week before and to have Grace read the entry about the suicide again (which I had told her we'd do). But Grace came in talking about some of the difficulties she felt at times within her family, at one point speaking about how it would be nice to have an older brother or sister to look out for her. She talked about her desire to have a family that really "stuck together" and "helped each other out." As she talked about this, she held her body, arms crossed in front of her. I asked, "How is it for you to be different from your family?” Perhaps in light of the writing Grace had done the week before, she talked about what it was like to feel like she had dealt with the situation alone at times and how she wished she could turn to her family more.

I brought up the last session a few times, but Grace did not want to talk in detail about it, and I decided to give her space and not push what I construed as my agenda, knowing that we would return to it. Indeed, Grace said that she would read the writing about the suicide again the following week, which would be the last session before her vacation. I was conscious that I wanted to do some containing, stabilizing work before her break so that she wouldn't feel raw and exposed while away, but also didn't think we should wait until after her vacation to return to the entry. I thought the longer we waited, the harder it might be to go back to that place.

In terms of the free writing assignment for session \#25, Grace chose to do a warm, comforting entry about Autumn and all that she loved about it, including sights, smells, tastes, etc. I noted that it was interesting that she had written about something that felt so nourishing and safe on the heels of such a challenging writing. Wanting to maintain the weekly writing assignment but not ready to assign her to write about the suicide from a first person perspective, I picked up on a theme from the session and asked Grace to write about "disappointment" as if it was a person. This personification of a feeling assignment was taken from a workshop I'd attended on journaling therapy (Adams, 2007).

The next week, in session \#26, Grace read aloud her entry on disappointment: "Write about disappointment as if it was a person." She also re-read the entry about the suicide, "Write about the suicide from a third person perspective" (assigned in session \#23, see Table 5). Interestingly, when reading about the suicide, this time Grace appeared to have a reaction to different parts than she had previously. For instance, she spoke of being able to hear her mother's voice, asking if her son was alive. We discussed the feeling of protectiveness Grace had towards her mother; she said she shied away from talking about the suicide with her because she didn't want to "put any more images in her head." Grace then spoke about having a desire to have her mother hold her and give her "wise advice.” I recalled how I'd thought of giving her a hug a few weeks before and made a connection to her verbalizing this need. 
When I asked Grace how it felt to go through the reading about the suicide again, she said it was hard but she knew there was a purpose to it. "We're really in the heart of this right now," I said, in an attempt to further mark the magnitude of where we were in the treatment. I shared with her my conflict about wanting to simultaneously guide her through this and also comfort her. In this moment, I was being honest about my struggle at times with the role of therapisthow sometimes doing what feels therapeutic also means you see your patients in some pain and turmoil-and she said, "I can't imagine how you do it. I appreciate you being strong for me. I have you to lean on...”

(My supervisor pointed out that the processing around the suicide had been hard, but that Grace was not coming apart. We discussed how I could have processed this even further with her, and had her potentially connect with her own voice in a deeper way. It's possible that my struggle with feeling "responsible" for initiating a phase of treatment which was so challenging for Grace prevented me from going even deeper. It did, however, feel like there was some movement in how she was talking about the incident. She didn't just feel wounded or overwhelmed, she also felt clearer and more empowered. Supervision helped to guide me and make me realize that my verbal intrusions weren't disorganizing Grace, as I feared, they were serving as guideposts to help contain her and also to help her label what she was feeling, something she was starting to own and accomplish more and more on her own.)

When Grace returned from vacation a few weeks later, in session \#27, she wasn't quite ready to pick up with the first person account of the suicide, which was to be the next writing assignment. She said that she would be ready to do it soon. At the end of this session, Grace spoke about her progress and how she felt she'd come a long way. She talked about her desire to start a family and how she couldn't imagine doing this while in the state she'd been in prior to beginning therapy and the process of self-exploration to which she'd been so dedicated. In this session, Grace also showed me a photo of the special chair where she did her writing. I shared with her that it was nice for me to be able to visualize her in this space.

(Again, supervision was invaluable as we examined some of Grace’s “resistance.” It was helpful for me to see the difference between chronic avoidance and normal resistance and how fear was one thing, but terror was another. Supervision allowed me to see that Grace's resistance was not chronic and immutable and she was not being terrorized. My desire to regulate the speed at which we accessed the more challenging material felt right. Especially in light of Grace's history of fluctuating between numbing and then feeling flooded, it was important to monitor the level and speed of processing. I wanted to validate her continued commitment without either pushing too hard or not pushing hard enough. Attaining a balance was an ongoing process.)

In the next few weeks, Grace wrote and then read about the suicide from a first person perspective. I assigned "Write about the suicide from a first person perspective" in session \#28, which she then read in session \#29. As Grace read this entry aloud, she was tearful, but steady in her telling of what she remembered. She was able to identify her affect as sad but also noted that she did not feel "as if she was back there”, i.e., having a flashback. (Grace had mentioned that 
when writing about the suicide, in both the third and first person, there were moments in which she felt as though she was having a flashback. However, she said that in reading the entries aloud to me, she did not experience this.) We noticed that each time she read or wrote about it, she recalled different aspects of what had happened. This time around, Grace made a connection to her relationship with her husband and how she hated it when he walked away from her in the middle of a fight. In these times, she would have a deep feeling of fear about him "giving up on" and abandoning her. We talked about how she had felt abandoned following the suicide, and how this may be playing a role in her fear that someone else dear to her might permanently leave. Thus with repeated writings and readings, we were able to process what the event had meant to her more wholly, and how it had impacted her cognitively, affectively, and relationally.

Grace shared that she was feeling more able to examine the suicide, and that she could "bounce back" more quickly after looking at it. She commented that she didn't feel she was at "square one" anymore. She said it was helpful to talk to me for a bit first in session each week as opposed to diving right in; this helped to mentally prepare her. Grace compared it to a physical workout, with a warm up, a more intense part of the workout, and a cool down. She said she appreciated this format. Overall, the therapy was helping her to receive protection in a way that she hadn't before, as well as explore how protection of others, while a genuine desire, also helped to guard her from feeling the horror and helplessness in a deeper way. In addition, the writing was helping her put words to a formerly more inchoate experience.

\section{Phase 3: Sessions 30-40}

\section{Sessions 30-33: Recollections of Past Anniversaries of the Suicide Versus this Year's}

For a little while, we moved away from the more intensive processing. Grace's father was dealing with a medical issue, and this was a focus for a few sessions. Interestingly, we also entered into a phase in which she was speaking about her family in a more realistic way and talking honestly about things they did that upset her. "I want to be treated the way I treat others," she said. "I expect to be accepted how I am." She was able to discuss her disappointment without feeling that this erased the love and affection she also had for them, i.e., simultaneously hold contrasting feelings toward them.

Around this time, Grace also had an experience with her mother at the cemetery where her brother was buried during which they spoke more openly about him. When Grace became upset, she physically leaned on her mother, who comforted her. "It was like her, me and (my brother) were there," sharing the moment, she told me. Thus, it felt that Grace was also absorbing the moments in which her needs were being met from her family, and accepting that while there may be limitations, there were times in which they were more connected around their shared experience.

The anniversary of the suicide was coming up and Grace noted that she wasn't dreading it as she had in years past. She said that she missed her brother, but that she felt different than she had in the past: calmer, more content, and happier in general. After the anniversary day had 
passed, in session \#31, Grace recounted how she had been feeling sad that evening and as if she wanted her husband to hold her. She asked him for this, he held and comforted her, and she felt better as a result. Grace was clarifying her needs and being more direct in asking for them. She said that her husband told her at the time, "It's okay, you're not there. I'm here, we're together." Thus, he was quite attuned and beautifully serving as a solid, secure object for her. Grace was also distinguishing her emotions in a more and more sophisticated way. "If I'm sad, I want to cry, not yell and scream and fight," she told me.

In session \#31, I gave Grace her last writing assignment, which was to write a reflective piece about the anniversary of the suicide in which she would compare and contrast her current self to how she had been on past anniversaries. She read this aloud in session \#32. "I feel a lot better," she said. "It will always be in my mind but I feel like I can live my life and it doesn't affect me every single day. I'm not going to let that run my life. It really did take over a lot of things (before) and I feel that I missed out on a lot.”

Grace discussed how this year, her feelings about the suicide hadn't built up prior to the anniversary date, as they had in past years. She said with the help of therapy and the writing, she was able to "pull" the feelings out of her and examine them. In the past, she would "freak out" because she didn't know how to express what she was feeling. "I'm more at ease now," she said. "In the past, I was angry, sad, confused and didn't know what to do with myself...this year, because of the writing, my true raw feelings were extracted." This beautifully illustrates Pennebaker's point that "repeatedly confronting an upsetting experience allows for a less emotionally laden assessment of its meaning and impact” (1997, p.95).

In session \#33, I took time to check in with Grace more fully about the writing in general, since we had come to an end with the "official" assignments. She shared that "one of the best and positive experiences I can take away is the writing. It helped me the most, it prepared me.” She spoke of the writing as helping her to identify the source of her feelings. We also talked about how the writing provided her with a good excuse to have time with herself. In addition, Grace felt that she was now more able to "believe” and "absorb" things now: "I'm like a sponge!" she said in one session. This in turn was deepening her relationships: "When my husband tells me I'm safe, now I hear it. I believe him.”

As we discussed this sense of expansion and growth, I found myself profoundly touched by what Grace was saying. "Without you, I wouldn't have been able to get to this point," she said. "You really helped me to see a lot of things." I told her that I saw these changes in her and how moved I was to be able to share in this with her. Grace said that she liked hearing that I could see the shifts. She commented that her husband said he saw them as well.

With all the solidifying that was happening, it felt like we were approaching a natural termination date, and so I took the next batch of sessions to celebrate this emergence of Grace's “true self” (Fosha, 2002b). 


\section{Sessions 34-40: Consolidation, Documenting Gains, Termination}

Early in this final phase of treatment, we determined a termination date approximately six to eight weeks in the future. In session \#34 Grace commented, "I feel like I could probably go to therapy for the rest of my life, but at the same time, I feel I've done a major thing - I've learned how to cope.” Some weeks later, in session \#38, Grace spoke of how therapy was like "a door that I'm never going to close." She continued, "I feel like it's ending, but it's not in a way. I'm still going to keep thinking about things and talking to people about things." Thus, it appeared that the treatment had laid the groundwork for more self-exploration and discovery. I was thrilled that Grace planned to continue the process of understanding herself, both on her own and in relation to the other people in her life.

My goals for this last phase of treatment were to review the work we had done together as well as go over what Grace would take away from the therapy. I planned to continue working in a relational, AEDP-influenced manner, including processing our relationship. Supervision was helpful in terms of helping me spark some of these dialogues, i.e., what was it about our relationship that helped you? How can you take that with you? What were your expectations of therapy? Any disappointments? I tried to keep questions like these in mind as we wound down. Grace readily talked about this with me and was honest that therapy had felt "a little scary" at first but that she had grown to like having a space in which to focus without distractions, and someone "on the outside who could give a fresh perspective. I feel like I find clarity here."

The last seven sessions served as time to consolidate what had been gained and discovered during treatment. It was a time to celebrate Grace's newly differentiated and individuated self: one who owned her needs and didn't feel guilty for it, one who knew how to take time out for herself, one who communicated more clearly, one who recognized the limitations of others and accepted them, and one who labeled her affect when it came up, trying to understand it without chasing it away or denying it.

In these sessions, we reviewed the ways in which Grace felt she had positively changed over the course of the therapy. Since these are directly relevant to outcome assessment, the results of this review are presented in section 8 below on qualitative indicators of outcome.

In the relational and AEDP vein, I continued to validate these positive shifts for Grace. I wanted to have her continue to experience the feeling of her true self "being seen" and keep relaying to her that I was witnessing this metamorphosis. I wanted to help her label these areas of change as well. Her capacity to be with another person and also be with herself without feeling the need to compulsively fill the space was notable. Her ability to connect in meaningful ways - with herself, with me, and also with the people close to her, especially her husband — had grown immensely. We also discussed more what the writing had meant to Grace; she said her journal was like her "own personal story."

In our last session (\#40), we spoke about how, after leaving therapy, Grace would continue on her own the kinds of work she had learned about in therapy. Grace reiterated that 
taking time for herself felt important and nourishing and that it was now something she enjoyed. We talked about her mixed emotions about ending: Grace explained that she knew it was "because I've progressed, so it feels good. But it's also sad." She spoke about how she was not "out in the dark" anymore, feeling like she had no one to turn to. Not only had her own selfawareness increased but she valued the relationships with those close to her in a different way than she had before. Furthermore, Grace commented, "I don't want everyone to be my friend. I want to be who I am." This was a big shift from the ingratiating young woman who had first presented for therapy. She spoke of these changes as being "liberating...like I'm unzipping my body and stepping out of it...I'm the real me.” This again spoke to Fosha's ideas of the true self and self-at-best. Grace spoke of the contrast in who she'd been pre-therapy vs. who she was now: "I know who I am now. This really saved me. I felt out of control. I felt alone." Later in the session she shared, "My life is so different. It's finally nice to feel like who I really am."

I spent much of the last session feeling gratified that Grace had allowed me to enter her inner world in such a deep and meaningful way. I tried to relay this to her as best as I could. At the end of the session, Grace asked if she could hug me. This brought to mind my instinct to hug her months earlier, when she was in the midst of intensively processing the suicide and its impact on her. As I hugged Grace, I was happy to have a gesture which felt like a marker to the end of a meaningful therapy relationship.

\section{THERAPY MONITORING AND USE OF FEEDBACK INFORMATION}

Ongoing monitoring in the form of supervision and DVD review occurred throughout the treatment. Both my supervisor and I would review the DVD of each session and then discuss it when we met. I also utilized Grace's case as the applied portion of a graduate course in ShortTerm Psychodynamic Therapy, and had the opportunity to review it on a few occasions with my peers who were enrolled in the class as well as my professor, who was also a clinician-yielding very helpful, critical feedback. Ongoing supervision in particular was helpful in aiding me in making alterations throughout the course of treatment, especially because my supervisor made it a point to review the DVD in its entirety each week. Her attention to detail allowed for an intensive, collaborative supervisory experience. All of the supervision-both individual and peer-I received was immensely helpful in the development of my treatment approach.

I also used two quantitative, self-report measures, the Trauma Symptom Inventory (TSI) and the Outcome Questionnaire-45 (OQ-45). As mentioned earlier, I did not have the chance to use these at the start of treatment. Grace instead filled them out toward the end of treatment. At my request, she also filled out another set as she remembered her psychological state pretreatment. So, again, while this is not a standard, psychometrically valid administration of these measures, it does provide Grace's subjective view of her growth and progress from before treatment to after. (See Table 2 and Table 3 for Grace's pre and post scores on both measures.) 


\section{CONCLUDING EVALUATION OF THE THERAPY'S PROCESS AND OUTCOME}

\section{The Outcome of Grace's Therapy}

The quantitative and qualitative data from Grace's case provide a variety of indicators of a favorable outcome, as detailed below. Grace's levels of symptomatology and distress were decreased by the end of treatment. Her motivation was a key component of why I believe this treatment was successful. Grace's dedication to treatment as well as her willingness to form a rapport with me contributed greatly to our working relationship.

\section{Quantitative Results}

Table 2 presents the changes in Grace's scores on the Trauma Symptom Inventory. As can be seen, all five scales that were initially above 60 (i.e., one standard deviation above the clinical norm) decreased to a level below the clinical norm. The average decrease for these five scales was 16.6 points, or 1.66 standard deviations, indicating a sizable and clinically meaningful decrease in her PTSD-related symptoms.

Table 3 presents the changes in Grace's scores on the OQ-45. On three of the scalesTotal, Symptom Distress, and Interpersonal Relations - she began treatment with a score above the clinical cut-off point, and on all three she ended up not only below the clinical cut-off point, but also to a degree that far exceeded statistical significance on Jacobson and Truax's (1991) Reliable Change Index. Again, these results indicate highly meaningful reduction of clinical symptoms associated with PTSD and its ramifications.

As a qualification to the above results, it should be remembered that the results in Tables 2 and 3 are based on Grace's completing of the measures in a non-standard manner. Specifically, at the end of treatment, she completed the measures from two perspectives: how she felt at the end of treatment, and how she retrospectively remembered feeling at the beginning of therapy.

\section{Qualitative Results}

As described above in section 6 on the course of therapy, the last seven sessions were devoted in part to documenting the gains that Grace had achieved in therapy. These can be summarized as follows:

- Grace was no longer having anger outbursts on a regular basis. She had learned how to cope with different feelings, and now had tools that she hadn't had before. "I don't always feel trapped, like I want to jump out of my skin," she commented in session \#37. "If I'm upset, I talk about what's bothering me.” Grace spoke of how she had hated the way these meltdowns felt and that they had been a primary motivator for coming to therapy. She had been tired of feeling so upset, angry and powerless. Grace contrasted how she had been pretherapy, when these meltdowns were so familiar, to now, when she said she rarely got to that 
place. Before, she said, “I didn’t realize I had any choices or options.”

- Grace was now more comfortable standing up for herself, and both differentiating and owning her feelings. She was not as harsh on herself as she had been before, and didn't worry as much about what others might think about her.

- Grace was rarely having flashbacks or intrusive thoughts, and when she did, she now recognized what was happening; she was not nearly as activated as she had been in the past. In addition, she had learned to self-soothe when she was upset, as well as seek out others who helped her to feel regulated.

- Grace had achieved increased contentment, calmness, and happiness. She was more at ease in her body and not so anxious or frantic.

- Grace reported that her relationship with her husband was better than it had been and that he could see a difference in her. Further, concerning place in the family, she said, "I don't have to be who they want me to be." She spoke of no longer classifying herself as an outsider, even while acknowledging the ways in which she was different. These unique qualities had become something she could own, instead of something that marked her as an outcast.

Based on the quantitative and qualitative results listed above and in section 6 on the course of therapy, it would seem that the therapy was able to meet most, if not all, of the goals laid out in the treatment plan in section 5:

GOAL 1: To decrease Grace’s irritability and other PTSD-related symptoms.

GOAL 2: To help Grace grieve in a genuine way instead of anxiously describing.

GOAL 3: To establish a genuine attachment with Grace and develop trust and safety.

GOAL 4a: To slow Grace down so that she could begin to identify a range of feelings and increase her affect tolerance.

GOAL 4b: To work within the AEDP Triangle of Experience and go beneath the defense and anxiety points to reach core affect.

GOAL 4c: To challenge Grace’s defenses while maintaining our bond.

GOAL 5: To expose Grace to her traumatic memories and work on integrating them into a more linear narrative.

GOAL 6: To increase Grace’s ability to be alone and to claim time and space for herself.

GOAL 7: To solidify Grace’s sense of self, i.e., her "self-at-best” or "true self.” 
In sum, many changes were seen in Grace from the beginning to the end of treatment. Her posttraumatic symptoms, including irritability, anger, and intrusive thoughts, decreased. For the first time, Grace was able to deeply process her index trauma. She was able to meaningfully connect and stay with what was at times challenging affect. She was able to form a trust in me and in the work we were doing together. Her ability to regulate both her affect and levels of anxiety improved, as did her ability to self-soothe. Her relationships with those close to her, including her spouse and some of her family members, deepened. Her ability to recognize people's potential limits as well as to accept genuine nurturing and support improved. Her need for control subsided and her sense of self felt stronger and more clearly defined.

\section{Discussion of the Broader Issues Raised by Grace's Case}

\section{PTSD from a Single Traumatic Incident Versus "Complex PTSD”}

Much of the general writing about trauma survivors deals with cases of complex PTSD, including more complex diagnostic presentations and extensive histories of trauma. My treatment, on the other hand, focused on a survivor of a single traumatic incident. I found the AEDP-Writing treatment helpful when working in a more short-term manner with a singleincident trauma. For patients with more chronic trauma occurring during key developmental years, my model in its current form may not be the most appropriate form of treatment. According to van der Kolk (2005), children who grow up with caretakers who are "emotionally absent, inconsistent, frustrating, violent, intrusive, or neglectful” (p.403) are often deeply wounded in terms of capacity for trust and attachment. Indeed, van der Kolk continues, “...children with insecure attachment patterns have trouble relying on others to help them, while unable to regulate their emotional states by themselves” (p.403). Thus, for cases of complex PTSD, an ideal treatment would likely focus even more and for a longer period of time on support, rapport-building, stabilization, and affect containment and/or regulation before proceeding to any deeper affect or trauma exploration.

I had originally hoped to use three single-incident trauma survivors in my AEDP-Writing study. However, due to difficulties with the referral sources in locating this type of client, the two other cases I was assigned were not ideal candidates for the designated treatment. Each had extensive and complex histories of trauma, as well as either insecure or disorganized attachment styles. This was an important lesson learned: the proposed combination of AEDP and expressive writing is not a one-size-fits-all treatment, at least in its current format.

For instance, one patient I worked with, a 19-year old Caucasian female who presented with several symptoms of anxiety as well as fears of death and abandonment, had a history of chronic physical, verbal, and emotional abuse, as well as neglect. She did not have a single index trauma on which to focus, nor was she yet willing, ready, or able to examine her traumatic history. Our therapy was more about symptom reduction-her anxiety lessened during treatment-and planting seeds for the future, should she desire to process her history of abuse at some point. 
Another patient, a 47-year-old Caucasian woman, was overwhelmed by several aspects of her life. She told me that she was "not functioning" and that she had "complex PTSD." This patient too had a history of extensive trauma, starting with her mother's suicide when the patient was a child. The patient had made her own repeated suicide attempts over the course of twenty years, beginning at age seven. Due to her intensive current symptoms, tendency to become unraveled easily in session, and difficulty in consistently maintaining a linear narrative (both verbally and potentially internally), I sought more appropriate treatment for her than what I was providing. I did not feel that intense affect exploration was appropriate for this patient at this time, and that she instead needed a treatment that would be more containing and structured. Her multifaceted and complex diagnostic presentation included complex PTSD, an Axis II diagnosis, self-reported ADHD, and self-reported fibromyalgia.

\section{Lessons Learned about Expressive Writing from Grace's Case}

One question that was raised about the AEDP-Writing model in Grace's case was whether the writing exercises should have been more structured. In Grace's case, it felt organic to work in the way that I did, which was with some writing exercises pre-determined and a clear goal of writing about the index trauma, but with flexibility throughout about what types of writings I assigned. The overall goals of having Grace learn to be more comfortable with herself, develop her voice, and access deep parts of herself, including affect and at times painful memories-were achieved. However, in the future it might be more effective for the patient and the therapist if the specific exercises were more mapped out beforehand, although at the same time building in some discretion for the therapist to be able to adapt the writing to the client's particular preferences and life situation.

Of course the present case study is only about one case. It would be important in the future to try the AEDP-Writing model with a broad and diverse population, to see what the differences in responsiveness are from a cultural standpoint. While responsiveness is in some ways idiosyncratic, it would still be important to try this approach with a variety of patients in terms of dimensions like race, ethnicity, gender, and age. In terms of complex PTSD and different attachment styles, it's possible that the AEDP-Writing model could work if the phases were adapted to the individual needs of the clients who were not as ready as Grace was to process their traumatic experiences.

Finally, in the future, I would also utilize the quantitative measures earlier in the treatment, so as to obtain true "pre" and "post" scores. I also might want to arrange to have a pre-determined point at which to check in with the patient post-treatment. This would provide an opportunity to see if the effects of the treatment are ongoing.

Unfortunately, I did not arrange with Grace to have any follow-up contact. This felt like a contained therapy, with her driving the length of it, determined by her growing autonomy, improved self-image, and lessening of acute posttraumatic symptoms. It felt to me that the end of our working together was a corrective emotional experience, since it was not a loss that happened "to” Grace in a sudden and devastating manner, as her brother’s suicide had. Instead, 
it was a natural end that was initially driven by Grace and then mutually determined by the two of us. I did leave Grace with my contact information at the clinic should she desire to be in touch in the future.

\section{REFERENCES}

Abbass, A. A., Hancock, J. T., Henderson, J., \& Kisely, S. (2006). Short-term psychodynamic psychotherapies for common mental disorders. Cochrane Database of Systematic Reviews, Issue 4, Article No. CD004687.

Adams, K.A. (1990). Journal to the self. New York: Grand Central Publishing.

Adams, K. (2007). The power of journal therapy: Writing as a therapeutic tool. (Workbook provided at conference on journal therapy, 5/18/07).

Ainsworth, M.D.S., Blehar, M.C., Waters, E., \& Wall, S. (1978). Patterns of attachment: A psychological study of the strange situation. Hillsdale, NJ: Erlbaum.

American Psychiatric Association: Diagnostic and Statistical Manual of Mental Disorders, Fourth Edition, Text Revision. Washington, DC, American Psychiatric Association, 2000.

American Psychological Association. (2006). Accelerated experiential dynamic psychotherapy with Diana Fosha, PhD. Part of the systems of psychotherapy video series. Retrieved May 1, 2010 from http://www.apa.org/pubs/videos/ 4310759.aspx

Bowlby, J. (1973). Attachment and loss: Vol. 2. Separation. New York: Basic Books.

Bowlby, J. (1980). Attachment and loss: Vol. 3. Loss, sadness, and depression. New York: Basic Books.

Bowlby, J. (1982). Attachment and loss: Vol. 1. Attachment (2d ed.) New York: Basic Books.

Briere, J. (1995). Trauma symptom inventory professional manual. Odessa, FL: Psychological Assessment Resources.

Calhoun, K.S., \& Resick, P.A. (1993). Post-traumatic stress disorder. In Barlow, D.H. (Ed.). Clinical handbook of psychological disorders: A step-by-step treatment manual (2nd ed.), pp. 48-98. New York: Guilford Press.

Courtois, C. (1999). Recollections of sexual abuse: Treatment Principles and Guidelines. New York: Norton.

Damasio, A.R. (1999). The feeling of what happens: Body and emotion in the making of consciousness. New York: Harcourt Brace.

Davanloo, H. (Ed.). (1980). Short-term dynamic psychotherapy. New York: Jason Aronson.

Elliott, R. (2001). Contemporary brief experiential psychotherapy. Clinical Psychology: Science and Practice, $8,38-50$.

Esterling B.A., L’Abate, L., Murray, E., \& Pennebaker, J.W. (1999). Empirical foundations for writing in prevention and psychotherapy: Mental and physical health outcomes. Clinical Psychology Review, Vol. 19, 79-96.

Fosha, D. (2000). The transforming power of affect: A model for accelerated change. New York: Basic Books.

Fosha, D. (2002a). Trauma reveals the roots of resilience. Constructivism in the Human Sciences, 6 (1\&2), 7-15. Special September $11^{\text {th }}$ issue. 
Fosha, D. (2002b). True self, true other and core state: Toward a clinical theory of affective change process. Paper presented at the Los Angeles Psychoanalytic Society and Institute, Los Angeles, February 28, 2002.

Fosha, D. (2003). Dyadic regulation and experiential work with emotion and relatedness in trauma and disorganized attachment. In Solomon, M.F. \& Siegel, D.J. (Eds.), Healing trauma: Attachment, mind, body, and brain (pp.221-281). New York: W.W. Norton \& Company.

Fosha, D. (2006a). Quantum transformation in trauma and treatment: Traversing the crisis of healing change. Journal of Clinical Psychology: In session, Vol. 62 (5), 569-583.

Fosha, D. (2006b). Accelerated experiential dynamic therapy. Video from the series, Systems of psychotherapy video series. Washington, D.C.: American Psychological Association.

Fosha, D. (2007). The transformational arc in AEDP: Dyadic affect regulation and the metaprocessing of attachment, emotion, and transformation. Handout from AEDP Seminar Series, February 9, 2007, New York City.

Fosha, D., \& Slowiaczek, M.L. (1997). Techniques to accelerate dynamic psychotherapy. American Journal of Psychotherapy, 51, 229-251.

Gidron, Y., Peri, T., Connolly, J.F., \& Shalev, A.Y. (1996). Written disclosure in posttraumatic stress disorder: Is it beneficial to the patient? Journal of Nervous \& Mental Disease, 184 505-507.

Gleiser, K., Ford, J., \& Fosha, D. (2008). Contrasting exposure and experiential therapies for complex posttraumatic stress disorder. Psychotherapy: Training, Research, Theory, Practice, 45 (3), 340-360.

Greenberg, L.S., \& Paivio, S.C. (1997). Working with emotions in psychotherapy. New York: Guilford Press.

Greenberg, L.S., \& Safran, J. (1989). Emotion in psychotherapy.American Psychologist, 44, 1929.

Greenberg, L.S.,\& Watson, J.C. (2005). Emotion-focused therapy for depression. Washington, D.C.: American Psychological Association.

Herman, J. (1992). Trauma and recovery: The aftermath of violence-from domestic abuse to political terror. New York: Basic Books.

Jacobs, B. (2004). Writing for emotional balance. California: New Harbinger Publications, Inc.

Jacobson, N.S., \& Truax, P. (1991). Clinical significance: A statistical approach to defining meaningful change in psychotherapy research. Journal of Consulting and Clinical Psychology, 59, 12-19

Lambert, M.J., Burlingame, G.M., Umphress, V., Hansen, N.B., Vermeersch, D.A., Clouse, G.C, \& Yanchar, S.C. (1996). The reliability and validity of the outcome questionnaire. Clinical Psychology \& Psychotherapy, 4, 249-258.

Larsen, A.E. (2002). Integrating attachment and affect theory with short-term dynamic psychotherapy. Contemporary Psychology APA Review of Books, Vol. 47, No.5, pp.583585.

Levenson, H. (1995). Time-limited dynamic psychotherapy: A guide to clinical practice. New York: Basic Books. 
Lindner, V. (2004). The tale of two Bethanies: Trauma in the creative writing class. New Writing: The International Journal for the Practice and Theory of Creative Writing, Vol. 1 , Issue 1.

Lipton, B., \& Fosha, D. (In press 2010). Attachment as a transformative process in AEDP: Operationalizing the intersection of attachment theory and affective neuroscience. Journal of Psychotherapy Integration.

Malan, D.H. (1976). The frontier of brief psychotherapy. New York: Plenum Press.

McLeod, J. (2004). The significance of narrative and storytelling in postpsychological counseling and psychotherapy. In Lieblich, A., McAdams, D.P. \& Josselson, R. (Eds.), Healing plots: The narrative basis of psychotherapy (pp.11-27). Washington, DC: American Psychological Association.

McWilliams, N. (1994). Psychoanalytic diagnosis. New York: Guilford Press.

Messer, S.B. \& Warren, C.S. (1995). Models of brief dynamic psychotherapy: A comparative approach. New York: Guilford.

Murray, B. (2002). Writing to heal. Monitor on Psychology, Vol. 33, No. 6.

Panksepp, J. (1998). Affective neuroscience: The foundations of human and animal emotions. New York: Oxford University Press.

Pass, E. R. (2010). Combining expressive writing with an affect- and attachment-focused psychotherapeutic approach in the treatment of a single-incident trauma survivor. Unpublished doctoral dissertation, Rutgers University, Piscataway, NJ. Available at: http://rucore.libraries.rutgers.edu/search/results.php?rtype\%5B\%5D=\&key=DLR\&query =erica+pass

Pennebaker, J.W. \& Beall, S. (1986). Confronting a traumatic event: Toward an understanding of inhibition and disease. Journal of Abnormal Psychology, 95, 274-281.

Pennebaker, J.W. , Kiecolt-Glaser, J.K., \& Glaser, R. (1988). Disclosure of traumas and immune function: Health implications for psychotherapy. Journal of Consulting and Clinical Psychology, Vol. 56, pp. 239-245.

Pennebaker, J. (1997). Opening up: The healing power of expressing emotions, revised edition. New York: Guilford Press.

Pennebaker, J. (2004). Writing to heal: A guided journal for recovering from trauma and emotional upheaval. California: New Harbinger Publications, Inc.

Pennebaker, J.W. \& Seagal, J.D. (1999). Forming a story: The health benefits of narrative. Journal of Clinical Psychology, Vol. 55 (10), 1243-1254.

Ramirez-Esparza, N. \& Pennebaker, J.W. (2006). Do good stories produce good health? Exploring words, language, and culture. Narrative Inquiry, 16:1, 211-210.??

Resick, P.A., Monson, C.M., \& Rizvi, S.L. (2008). Post-traumatic stress disorder. In Barlow, D.H. (Ed.). Clinical handbook of psychological disorders: A step-by-step treatment manual (4th ed.), pp. 65-122. New York: Guilford Press.

Robinson, M. (2000). Writing well: Health and the power to make images. Journal of Medical Ethics, 26:79-84.

Rogers, C. R. (1951). Client centered therapy. Boston: Houghton Mifflin.

Russell, E. \& Fosha, D. (2008). Transformational affects and core state in AEDP: The emergence and consolidation of joy, hope, gratitude and confidence in the (solid goodness of the) self. Journal of Psychotherapy Integration, 18 (2): 167-190. 
Schore, A.N. (1994). Affect regulation and the origin of the self: The neurobiology of emotional development. Hillsdale, NJ: Erlbaum.

Shedler, J. (2010). The efficacy of psychodynamic psychotherapy. American Psychological Association, 65, 98-109.

Smyth, J.M. (1998). Written emotional expression: effect sizes, outcome types, and moderating variables. Journal of Consulting and Clinical Psychology, 66:174-184.

Smyth, J., True, N. \& Souto, J. (2001). Effects of writing about traumatic experiences: The necessity for narrative structuring. Journal of Social and Clinical Psychology, Vol. 20, No.2, pp. 161-172.

Society of Clinical Psychology (2010). Website of research-supported psychological treatments. Available: http://www.div12.org/PsychologicalTreatments/index.html

Van der Hart, O., Brown, P. \& Van der Kolk, B.A. (1989). Pierre Janet's treatment of posttraumatic stress. Journal of Traumatic Stress. Vol.2 (4), pp. 379-395

van der Hart, O., Steele, K. \& Ford, J.D. (2000). Introducing issues in the treatment of complex PTSD. Traumatic Stress Points, 15(4), 10-11

van der Kolk, B.A. (1994). The body keeps the score: Memory and the evolving psychobiology of post traumatic stress. Harvard Review of Psychiatry, 1(5), 253-265.

van der Kolk, B.A. (2005). Developmental trauma disorder: Towards a rational diagnosis for children with complex trauma histories. Psychiatric Annals, 35, 401-408.

Winnicott, D. W. (1960/1965). Ego distortion in terms of true and false self. In The maturational process and the facilitating environment (pp. 140-152). New York: International Universities Press.

Winnicott, D. W. (1965). The maturational process and the facilitating environment. New York: International Universities Press. 


\section{Table 1. Inclusion and Exclusion Criteria}

\begin{tabular}{|c|c|}
\hline Inclusion Criteria & Exclusion Criteria \\
\hline $\begin{array}{l}\text { 1. Subjects will be between } 18 \text { and } 55 \text { years of } \\
\text { age. }\end{array}$ & $\begin{array}{l}\text { 1. Inability to engage in meaningful } \\
\text { verbal exchange with the clinician due } \\
\text { to impairment such as, but not limited } \\
\text { to: psychosis, dementia, developmental } \\
\text { disability, severe problems with } \\
\text { attention and concentration, or } \\
\text { diminished intellectual capacities } \\
\text { (Levenson, 1995). }\end{array}$ \\
\hline 2. Subjects will be fluent in English. & $\begin{array}{l}\text { 2. The patient's presenting problem can } \\
\text { be more effectively treated via other } \\
\text { means (e.g., specific phobia, etc.) } \\
\text { (Levenson, 1995). }\end{array}$ \\
\hline $\begin{array}{l}\text { 3. Subjects will be presenting for treatment } \\
\text { seeking relief from the after-effects of a } \\
\text { traumatic event. }\end{array}$ & $\begin{array}{l}\text { 3. The subject engages in behaviors that } \\
\text { threaten to significantly interfere with } \\
\text { the treatment process and/or pose the } \\
\text { risk of harm to self or other (e.g., } \\
\text { impulse-control problems, drug and/or } \\
\text { alcohol abuse, current suicidality) } \\
\text { (Levenson, 1995). }\end{array}$ \\
\hline $\begin{array}{l}\text { 4. Subjects must be experiencing sufficient } \\
\text { emotional distress to be motivated to engage in } \\
\text { treatment (Levenson, 1995). }\end{array}$ & \\
\hline $\begin{array}{l}\text { 5. Subjects must possess enough trust and hope } \\
\text { for relief that they are willing to come for } \\
\text { regular appointments and to talk candidly } \\
\text { about themselves (Levenson, 1995). }\end{array}$ & \\
\hline $\begin{array}{l}\text { 6. Subjects must have the capacity to distance } \\
\text { themselves emotionally from their feelings so } \\
\text { that they may be examined (Levenson, 1995). }\end{array}$ & \\
\hline $\begin{array}{l}\text { 7. The subject's personal history should } \\
\text { suggest a capacity to relate to the clinician and } \\
\text { to tolerate separation between sessions and at } \\
\text { the end of treatment without experiencing } \\
\text { intense discomfort (Levenson, 1995). }\end{array}$ & \\
\hline
\end{tabular}


Approach in the Treatment of a Single-Incident Trauma Survivor: The Case of "Grace"

E.R. Pass

Pragmatic Case Studies in Psychotherapy, http://pcsp.libraries.rutgers.edu

Volume 8, Module 2, Article 1, pp. 60-112, 05-22-12 [copyright by author]

Table 2. Grace's Scores: Trauma Symptom Inventory

\begin{tabular}{|l|c|c|}
\hline & PRE (in T score) & POST (in T score) \\
\hline VALIDITY SCALES & & \\
\hline Response Level & $45^{*}$ & 45 \\
\hline Atypical Response & 41 & 41 \\
\hline Inconsistent Response & 51 & 43 \\
\hline CLINICAL SCALES & & 54 \\
\hline Anxious Arousal & $55^{*}$ & 45 \\
\hline Depression & 61 & 48 \\
\hline Anger/Irritability & 69 & 57 \\
\hline Intrusive Experiences & 71 & 51 \\
\hline Defensive Avoidance & 55 & 45 \\
\hline Dissociation & 55 & 49 \\
\hline Sexual Concerns & 48 & \\
\hline $\begin{array}{l}\text { Dysfunctional Sexual } \\
\text { Behavior }\end{array}$ & 49 & \\
\hline Impaired Self-Reference & 68 & \\
\hline Tension Reduction Behavior & 64 & \\
\hline
\end{tabular}

* Scores are in the form of "T-scores," meaning that the mean for the nonclinical standardization sample is 50, and the standard deviation is 10 . Note that the standardization sample was designed to be representative, based on a variety of both age and gender groupings. 
Table 3. Grace’s Scores: Outcome Questionnaire-45

\begin{tabular}{|l|l|l|l|l|l|l|}
\hline $\begin{array}{l}\text { A. } \\
\text { Scale }\end{array}$ & $\begin{array}{l}\text { B. } \\
\text { Range } \\
\text { of } \\
\text { Scores }\end{array}$ & $\begin{array}{l}\text { C. } \\
\text { Clinical } \\
\text { Cut-Off } \\
\text { Point }\end{array}$ & $\begin{array}{l}\text { D. } \\
\text { "Pre" Score } \\
\text { at the } \\
\text { Beginning } \\
\text { of Therapy }\end{array}$ & $\begin{array}{l}\text { E. } \\
\text { "Post" } \\
\text { Score at } \\
\text { End of } \\
\text { Therapy }\end{array}$ & $\begin{array}{l}\text { F. } \\
\text { Decrease } \\
\text { Between } \\
\text { "Pre" and } \\
\text { "Post" } \\
\text { Scores }\end{array}$ & $\begin{array}{l}\text { G. } \\
\text { Decrease } \\
\text { Level for } \\
\text { Statistical } \\
\text { Significance } \\
\text { on RCI }\end{array}$ \\
\hline Total Score & $0-180$ & $63 \#$ & 72 & 18 & $54^{*}$ & 14 \\
\hline $\begin{array}{l}\text { Symptom } \\
\text { Distress Score }\end{array}$ & $0-100$ & 36 & 42 & 9 & $33^{*}$ & 10 \\
\hline $\begin{array}{l}\text { Interpersonal } \\
\text { Relations } \\
\text { Score }\end{array}$ & $0-44$ & 15 & 18 & 0 & $18^{*}$ & 8 \\
\hline $\begin{array}{l}\text { Social Role } \\
\text { Score }\end{array}$ & $0-36$ & 12 & 12 & 9 & 3 & 7 \\
\hline
\end{tabular}

\# Higher scores indicate more clinical symptoms and/or more impaired functioning.

* Decrease between "pre" and "post" scores statistically significant via Jacobson and Truax's (1991) Reliable Change Index (see comparison between columns F and G). 
Pragmatic Case Studies in Psychotherapy, http://pcsp.libraries.rutgers.edu

Volume 8, Module 2, Article 1, pp. 60-112, 05-22-12 [copyright by author]

\section{Table 4. Diagnosis at Beginning and End of Treatment}

\begin{tabular}{|c|c|c|c|c|}
\hline \multirow[b]{2}{*}{ Axis I } & \multicolumn{2}{|c|}{$\begin{array}{l}\text { DSM- IV Diagnosis at } \\
\text { Beginning of Therapy }\end{array}$} & \multicolumn{2}{|c|}{$\begin{array}{l}\text { DSM-IV Diagnosis at } \\
\text { End of Therapy }\end{array}$} \\
\hline & 309.81 & $\begin{array}{l}\text { Posttraumatic } \\
\text { Stress Disorder }\end{array}$ & V71.09 & No diagnosis \\
\hline Axis II & V71.09 & $\begin{array}{l}\text { No diagnosis } \\
\text { (investigate } \\
\text { potential dependent } \\
\text { personality } \\
\text { features) }\end{array}$ & V71.09 & No diagnosis \\
\hline Axis III & & Asthma & & Asthma \\
\hline Axis IV & & $\begin{array}{l}\text { Suicide of brother, } \\
\text { some discord in } \\
\text { close relationships }\end{array}$ & & $\begin{array}{l}\text { Suicide of } \\
\text { brother }\end{array}$ \\
\hline Axis V & & $\mathrm{GAF}=62$ & & GAF $=80$ \\
\hline
\end{tabular}


Approach in the Treatment of a Single-Incident Trauma Survivor: The Case of "Grace"

\section{E.R. Pass}

Pragmatic Case Studies in Psychotherapy, http://pcsp.libraries.rutgers.edu

Volume 8, Module 2, Article 1, pp. 60-112, 05-22-12 [copyright by author]

Table 5. Writing Assignments by Session*

\begin{tabular}{|c|c|c|}
\hline Session \# & Writing Assignment Given & Goal/Connection to rest of therapy \\
\hline 14 & Formally introduce writing. & \\
\hline 15 & $\begin{array}{l}\text { Write about a childhood } \\
\text { memory. }\end{array}$ & $\begin{array}{l}\text { Begin establishing familiarity and safety with } \\
\text { writing. Tap into a time when Grace was her } \\
\text { "true self.” }\end{array}$ \\
\hline 16 & Write a letter to a friend.** & $\begin{array}{l}\text { Continue to establish familiarity with } \\
\text { writing. Grace was having a hard time } \\
\text { communicating with a friend, and this was a } \\
\text { way to figure out what she wanted to say to } \\
\text { her. }\end{array}$ \\
\hline 17 & $\begin{array}{l}\text { Write about a good memory } \\
\text { you have of your brother. }\end{array}$ & $\begin{array}{l}\text { Begin to establish comfort writing about } \\
\text { Grace's relationship with her brother. }\end{array}$ \\
\hline 18 & $\begin{array}{l}\text { Write about how you } \\
\text { remember yourself in the } \\
\text { months preceding the } \\
\text { suicide. }\end{array}$ & $\begin{array}{l}\text { Begin to bring Grace mentally back to the } \\
\text { period of time during which the index trauma } \\
\text { took place. Begin to establish who she was } \\
\text { pre-trauma vs. post-trauma. }\end{array}$ \\
\hline 19 & $\begin{array}{l}\text { Write about a more } \\
\text { challenging memory you } \\
\text { have of your brother. }\end{array}$ & $\begin{array}{l}\text { Get closer to approaching the suicide in the } \\
\text { writing. }\end{array}$ \\
\hline 20 & Write a letter to your brother. & $\begin{array}{l}\text { Grace had been talking about how she } \\
\text { wished her brother was still around; this was } \\
\text { a way to communicate directly with him. }\end{array}$ \\
\hline 21 & $\begin{array}{l}\text { Write a list comparing } \\
\text { sources of stress with sources } \\
\text { of soothing in your life. }\end{array}$ & $\begin{array}{l}\text { After an intense session, this assignment } \\
\text { provided some containing and organization } \\
\text { for Grace. }\end{array}$ \\
\hline
\end{tabular}

* The session \# indicates the session in which the writing assignment was made. The writing was then read in the following session. The reading generally took between 3-10 minutes to complete.

** This was the only assignment that was not completed (see text). 


\section{Table 5. Writing Assignments by Session (continued)}

\begin{tabular}{|c|c|c|}
\hline 22 & $\begin{array}{l}\text { Write a comparison of who } \\
\text { you are now vs. who you } \\
\text { were at the time of the } \\
\text { suicide. }\end{array}$ & $\begin{array}{l}\text { This was to show Grace the progress she'd } \\
\text { made in the years since the suicide and to build } \\
\text { self-empathy for who she'd been then. }\end{array}$ \\
\hline 23 & $\begin{array}{l}\text { Write about the suicide } \\
\text { from a third person } \\
\text { perspective. }\end{array}$ & $\begin{array}{l}\text { This was the start of the direct processing of } \\
\text { the index trauma. I began with a third person } \\
\text { perspective to give Grace some distance from } \\
\text { the event. }\end{array}$ \\
\hline 24 & Free write assignment. & $\begin{array}{l}\text { After the intensive processing of this session, } \\
\text { during which Grace read the third person } \\
\text { account aloud, I wanted her to regain some } \\
\text { control and autonomy, so I suggested a "free } \\
\text { write." }\end{array}$ \\
\hline 25 & $\begin{array}{l}\text { Write about } \\
\text { disappointment as if it was } \\
\text { a person. }\end{array}$ & $\begin{array}{l}\text { This assignment directly pertained to } \\
\text { disappointment, which had been a theme of the } \\
\text { session. Grace said she was not yet ready to } \\
\text { write about the index trauma from a first } \\
\text { person perspective. }\end{array}$ \\
\hline 28 & $\begin{array}{l}\text { Write about the suicide } \\
\text { from a first person } \\
\text { perspective. }\end{array}$ & $\begin{array}{l}\text { This was the ultimate goal of the writing. Due } \\
\text { to vacation and some hesitation on Grace's } \\
\text { part, a few sessions lapsed before she felt ready } \\
\text { to tackle this. She had already done the third } \\
\text { person writing and read it aloud twice in } \\
\text { session. I now asked her to write about the } \\
\text { index trauma from an even more personal point } \\
\text { of view, that of a direct observer. }\end{array}$ \\
\hline 31 & $\begin{array}{l}\text { Write a comparison of } \\
\text { what this year's } \\
\text { anniversary of the suicide } \\
\text { was like for you vs. past } \\
\text { years. }\end{array}$ & $\begin{array}{l}\text { This assignment was the final writing, and it } \\
\text { was inspired by the content of the sessions. } \\
\text { Grace shared that as the anniversary of the } \\
\text { suicide approached, she felt different than she } \\
\text { had during past anniversaries. I took this } \\
\text { opportunity to have her compare where she } \\
\text { was this year vs. past years. I thought this } \\
\text { would be an appropriate final writing, and one } \\
\text { which would give us much to discuss in } \\
\text { session. }\end{array}$ \\
\hline
\end{tabular}

